ARID International Journal of Social Sciences and Humanities (AIJSSH) VOL.2, Special Issue (1), August 2020

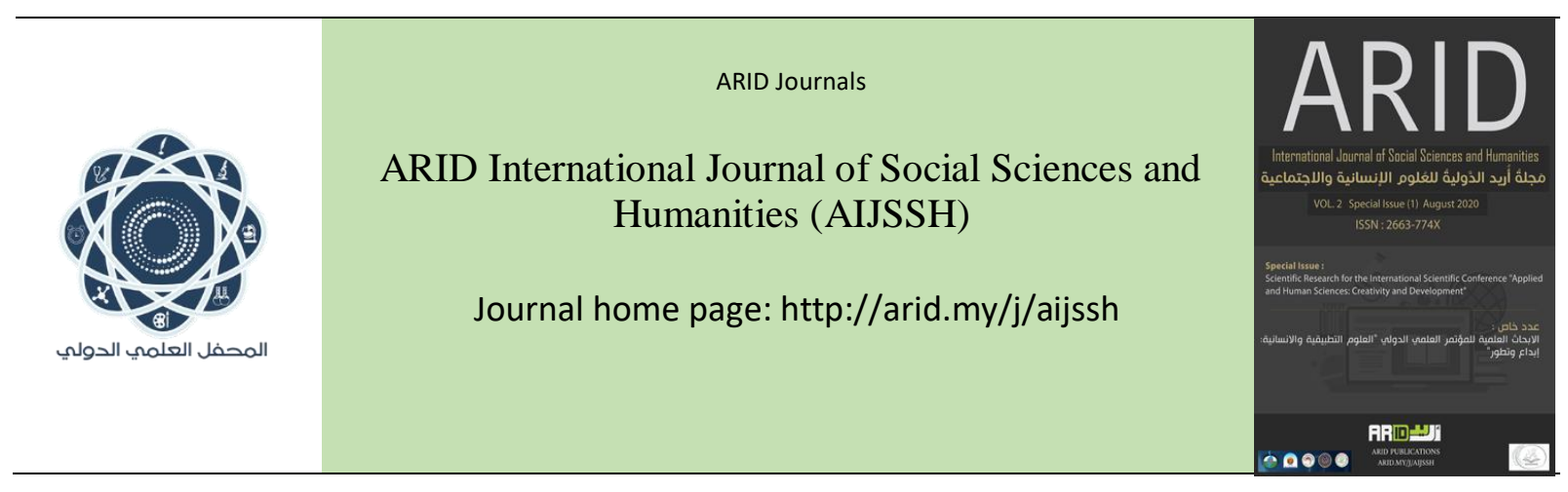

$$
\begin{aligned}
& \text { مَجلةُ أُريد الدَّوليةُ للعُلومج الإنسانية والإجتماعية } \\
& \text { المجلد الثاني ،العدد الخاص ، آب } 2020 \text { م }
\end{aligned}
$$

\title{
Electronic trading in the Iraqi market for securities: reality and ambition
}

$$
\begin{gathered}
\text { التداول الإكتروني في سوق العراق للأوراق المالية: الواقع والطموح . نغم حسين نعمة * * كلية اقتصاديات الأعمال -جامعة النهرين- العراق } \\
\text { الباحثة هبة مهدي صالح } \\
\text { naghamalnama @gmail.com } \\
\text { arid.my/0004-1771 } \\
\text { https:/doi.org/10.36772/arid.aijssh.2020.s.218 }
\end{gathered}
$$




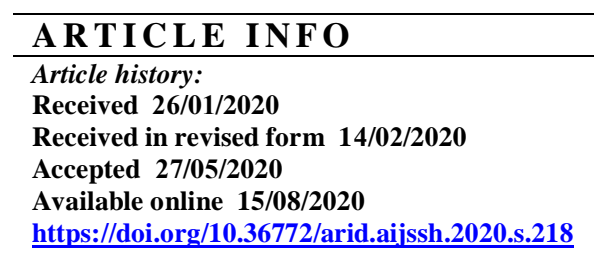

\begin{abstract}
The rapid development of information technology and its use in all fields has a positive influence on all fields, and financial markets have a share of this development through the use of an electronic trading system to settle transactions and enhance transparency and disclosure in all activities of these markets and stimulate their performance .

It is worth nothing that these revolutions remove the necessity for nonstop connection with persons through the internet or phone networks, The development in transportations expertise allows for quicker ordering then transfer of marketplace information to a bigger collection of participants .

The growing of electronic trading system on an global origin has been phenomenal, Central securities depository system is an integrated work system that of operations aims to control the movement of trading in the stock market and ensure the safety of operations, therefore legislation worked to organize the work of central securities depository some of them devoted complete laws that explain the features of this organization and everything related to its work . This study has reached a number of conclusions, perhaps the most important of them are that the use of the electronic trading system as an alternative to the to the manual trading and deposit system gave great flexibility and different information to brokers that made it easier for them to know the executed and unimplemented processes and carrying out an analysis of the conditions of the companies whose shares are traded faster and achieving transparency and safety for dealers .

The study has come out for a number of recommendations, perhaps the most important of them are that the big and correct procedure of the electronic trading mechanism must be continuous during the future period, it has a clear impact by avoiding human errors .
\end{abstract}




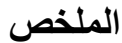

لقد كان للتطور السريع في تكنولوجيا المعلومات واستعمالها في كافة المجالات الأثر الإيجابي على كل المجالات، وقد كان

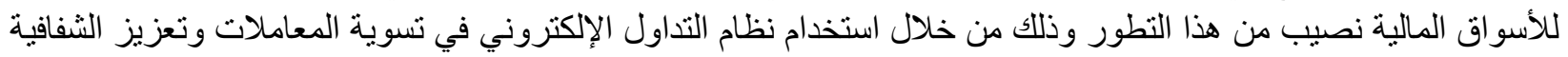

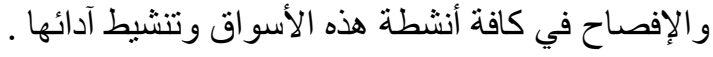
من الجدير بالذكر أن هذه الابتكارات تلغي الحاجة إلى الاتصال المباشر بالأشخاص، إنما بكون عن طريق شبكات الإنترنت

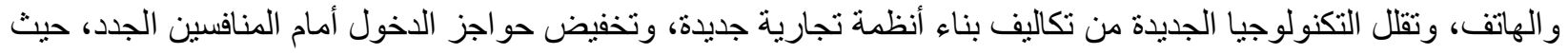

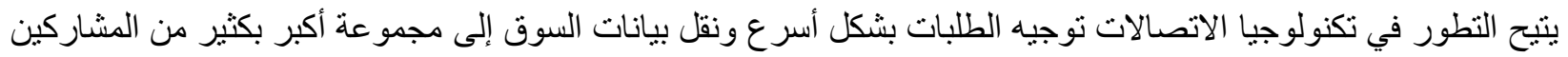

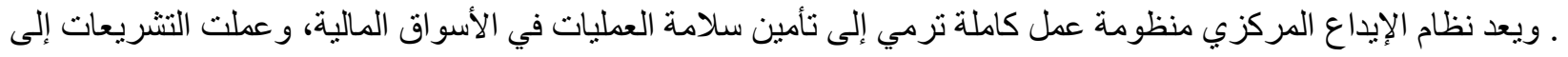

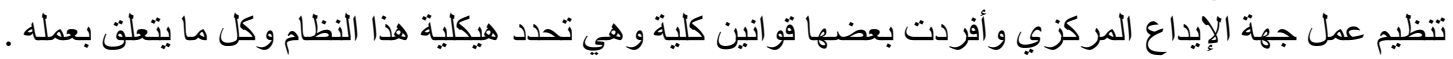

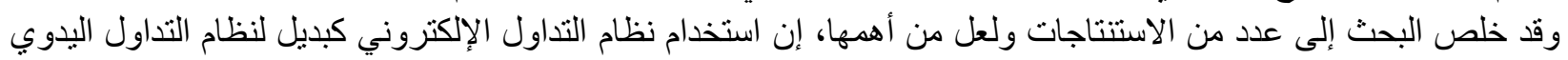

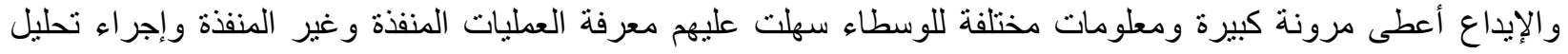

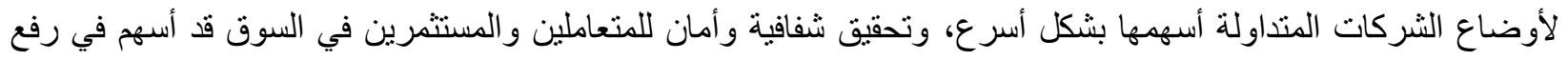
كفاءة وسر عة التعامل بالأوراق المالية. وقد خرج البحث لعدد من التوصيات ولعل من أهمها أن الإجر اء الكبير والسديد لآلية التداول الإلكتروني يجب أن يكون مستمر

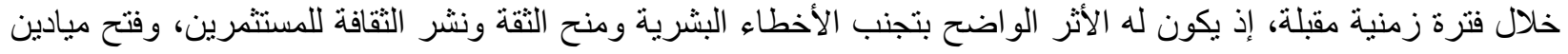

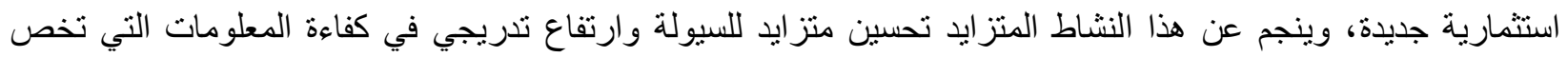

الكلمات المفتاحية: التداول الإكتروني، مؤشر ات التداول الإلكتروني، سوق العراق للأوراق المالية. 
إن تأثير التداول الإلكتروني على الأسواق المالية أمر مهم لكل من صناع السياسات و المشاركين في السوق، ويمكن أن ترتبط جودة السوق المالية بالنمو الاقتصادي و الرفاهية الاجتماعية للأفراد، الأمر الذي سيكون مصدر قلق لصناع السياسات، ويمكن أن تغير الأنظمة الإلكترونية بشكل كبير الطريقة التي تحكم بها الأسواق عن طريق تغيير الأسواق نفسها، وسيكون الأداء الفعال للنظام المالي مهما أيضا للمستثمرين، إذ كلما زادت كفاءة السوق انخفت تكلفة التناول للمستثر الفردي، وهذا من شأنه أن يزيد من ثروة المستثمر وسيكون صناع السوق، الذين يوفرون السيولة للسوق في نظام تقليدي أقل ميلًا لدعم التجارة الإلكترونية، لأنه يمكن القضاء على دور هم أو على الأقل تقليله من خلال التداول الإلكتروني، لأن السيولة يتم توفير ها من خلال أعداد كبيرة من المستثمرين الذين يمكن أن تجتذبه البورصة محليا وعالميا، ويجري تداول الأوراق المالية وفق نظام ينظم عملية التداول التي تعتبر سلسة متكاملة من الإجر اءات تبدأ من أمر الثراء أو البيع التي تصدر من المستثمر إلى أحد الوسطاء الماليين ومن ثم يقوم الوسيط بتنفيذ الأمر في سوق الأوراق المالية وينعقد عندها عقد التداول وهو التداول الإلكتروني حيث تأثير كبير على آداء أسواق الأوراق المالية كونه يقلل من تكلفة المعاملات عن طريق تقليل النفقات العامة المشاركة في إجر اء التداول، والتي يمكن أن تحفز المزيد من المستثمرين على الاستثمار، ويمكنه أيضا تقليل أو إزالة العديد من القيود المادية على التداول وتمكين حجم أكبر من التداول ويؤدي إلى الوصول إلى أسواف أكثر قدرة على التعامل مع كميات التداول، كونه يمكن اعتباره قوة تحول في الأسواق المالية .

\section{المنهجية العمية للاراسة}

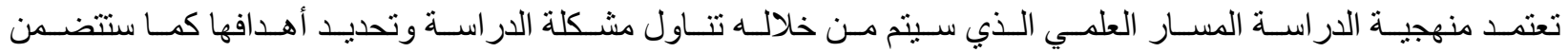
استعر اض أهمية الدراسة وتحديد فرضياتها وصو لاً للهدف المطلوب تحقيقه وكما ياتتي :

1) هل يؤثر نظام التداول الإلكتروني والإيداع المركزي في مؤشرات التداول في سوق العراق للأوراق المالية بعد تحويل النظام في السوق من نظام التداول اليدوي إلى نظام التداول الإلكتروني ؟

2) هل يؤدي نظام التداول الإلكتروني إلى جذب المزيد من المستثرين المحتملين لاستثمار أمو الهم في السوق المالية ؟ وهل أن نظام التداول الإلكتروني له أثر في نشر التوعية والثقافة الاستثمارية بين المتعاملين بالأوراق المالية في 


\section{2-2-2 2 - 2-2 أهداف الدراسة}

نسعى من خلال قيامنا بهذه الدر اسة العلمية إلى تحقيق جملة أهداف هي كالآتي :

1) معرفة أثر تحول نظام التداول اليدوي إلى نظام التداول الإلكتروني في سوق العراق للأوراق المالية .

2) توعية المستثرين لمعرفة نظام التداول الإلكتروني والإيداع المركزي من أجل زيادة مؤشرات التداول الإلكتروني

للأور اق المالية ورفع فرص الاستثمار في السوق بما يخدم ويطور وينهض من الاقتصاد الوطني .

\section{3-2-2 - 2 - 2 أهمية الدراسة}

تتبلور أهمية الدر اسة كونها تتناول موضوع غاية الأهمية في سوق العراق للأوراق المالية وفي ما يأتي أبرز النقاط:

1) تمثل هذه الدراسة أحد الدراسات التي تناولت موضو عا مهما تفتقر إليه المكاتب المحلية و العربية إلى حد سواء لاسيما

مع تصاعد وتيرة تكنولوجيا البيانات والمعلومات وشبكات الإنترنت الحديثة والمتطورة، فضلا عن ما يوفره نظام

التداول الإكتروني دقة في إتمام عمليات التداول المتنوعة بين المستثمرين .

2) تسليط الضوء على نظام التداول الإلكتروني إذ أن نظام التداول الإلكتروني يمتاز بالسرعة الفائقة وقلة التكاليف

والجهذ المبذول من قبل المستثرين .

3) إن لنظام التداول الإلكتروني أهمية كبيرة في نشر وعي وثقافة المستثمرين وتحفيز هم بما يحقق مستويات عالية من

الآداء و الفعالية في سوق الأوراق المالية وتوفر الثنفافية والإفصاح في إنجاز العمليات و الحفاظ على هوية المتداول . 


\section{المبحث الأول \\ مبادئ التذاول الإكتروني}

مبادئ التداول الإكتروني 1-1 نشأة نظام التداول الإكتروني

مرت آليات وطرق التداول بالأوراق المالية في الأسواق المالية المتقدمة بعدة مراحل، ارتبطت بنطور النظام الاقتصادي وفلسفة توظيف الأموال في تلك البلدان كما ارتبطت بحجم ونوع الخدمات المالية التي قدمتها اعتمادا على مبدأ حرية حركة و انتقال رؤوس الأمو ال و استثمار ها.

كانت النشأة الأولى للتداول بالأور اق المالية بدائية تعتمد مبادلة السلع والتسوية المالية وتوثيق المعاملة كأجر اء تجاري، وبسبب عدم اكتمال التسوية المالية في معظم الأحيان نشأت صكوك الدين كورقة مالية، وبسبب الحاجة إلى تسييل الأوراق المالية ظهرت أول أسواق الأوراق المالية، واعتمدت آليات التسجيل والتسوية اليدوية والإعلان عن الأسعار للأوراق المالية بطريقة المناداة والمزايدة العلنية ثم الاعتماد الكامل على التكنولوجيا المنطورة في كل عمليات نسجيل أوامر البيع والثراء المتتوعة و القيام بأجر اء التسويات اللحظية بصورة إلكترونية كاملة لا تستغرق سوى أجزاء الثانية الواحدة، إذ أن التعليمات المحددة من قبل الأسواق المالية المنظمة في مختلف الدول وضعت مجمو عة من الإجراءات التي تهدف إلى ضمان تحقيق العدالة الكاملة للبائعين و المشترين وتحقيق دقة وسر عة العمليات المالية من خلال الوسطاء الذين يقومون بالالنز ام التنفيذ أية أوامر تصل إليهم من وكلائهم في سجل أوامر السوق وفق التاريخ الذي وردت فيه الأوامر وبالأسعار المقتصرة لكل أمر. [1] شهد سوق الأسهم الأمريكي (Nasdaq) إجر اءات تنظيم و إطلاق لنظام التداول الإلكتروني عام 1971، تزامنا مع إطلاق شبكة الاتصالات الإلكترونية وبروز دور الوسطاء في السوق لنشر معلومات التداول والسماح باستخدام النظام والتخلي عن التداول اليدوي، وبدأت الأسواق المالية تعتمد الأنظمة الإلكترونية في مختلف البلدان الأوربية تباعا للسوق الأمريكي باستخدام تكنولوجيا التداول والحفظ والتسوية المالية للتداول الإلكتروني التي قادت إلى ربط النظم المالية للبلدان، وتم استخدام نظام التداول الإلكتروني في الأسواق المالية ليس فقط لتحسين قائمة عمليات التداول ولكن لتغيير الهيكل العام للتداول. [2] 
ومع استخدام شبكات الإنترنت، اعتمدت العديد من الأسواق المالية في الدول العربية والأجنبية آليات منطورة لتداول الأوراق المالية عبر شبكة الإنترنت لجذب المزيد من الثرائح الجديدة من المستثرين، لم تكن منوفرة سابقا على صعيد سوق الأوراق

وعلى مدى العشرين سنة الماضية بدأ استبدال نظام التداول اليدوي في الأسواق المالية بنظام التداول الإلكتروني بشكل تدريجي، حيث تطورت ثقافة الوسطاء و المستثمرين في الأسواق المالية، وشهدت الأسواق المالية توظيف أشخاص غير تقليدين في عملهم، إذ تنو عت الوظائف منها المهندسين والفيزيائيين وعلماء الكومبيوتر، كما أنهم اعتمدوا استخدام تطبيقات غير معقدة التركيب، من خلال منصات التداول الإكترونية التي امتازت بأنها ذات معدل قوة وسرعة قياسية، وهذا التطور زاد من

$$
\text { عمليات تداول الأوراق المالية في الأسواق المالية. [4] }
$$

أصبحت التعاملات المحلية والتعاملات الدولية ذات سهولة ويسر، من خلال اتصال الأسواق المالية العالمبة مع بعضها البعض بشبكة الاتصالات الدولية عن طريق نظام "Big Bang "2 ابتكر هذا النظام الفكر البريطاني، فغدت الأسواق المالية العالمية منصلة مع بعضها البعض، وعن بداية العمل بهذا النظام، ففي عام 1985 نوارد كلام بأن "نظام بيغ بانغ" عبارة عن ثورة للتقنية التكنولوجية في أواخر القرن العشرين ـ إذ بإمكان المستثر أن يقوم بشراء أو بيع الأسهم لأي شركة وبأب سوق مالية عالمية خلال وقت قصير جدا لا بتعدى ثوان، مما يدل على أن الأسواق المالية في العالم أصبحت سوق مالية واحدة، ويكمن التحدي الكبير الذي يواجه الأسواق المالية من أجل إلغاء أعداد هائلة من البيانات والمعلومات المتداولة بصورة تقليدية، وتحويلها لمعلومات قابلة للتداول بصورة إلكترونية سريعة مواكبة للتطورات الحاصلة في مجال الأعمال، تقوي الأنشطة الاستثمارية التي يتعامل بها المستثرون بصورة عامة في الأسواق المالية [5] ، و هو يمثل بذللك ثورة عملية يقوم بتسهيل عمليات الصفقات بسهولة وشفافية مما أدى إلى زيادة ثقة المستثمرين بسوق الأوراق المالية. [6] 1-2 مفهوم نظام التداول الإكتروني هناك أكثر من مفهوم للتداول الإلكتروني وكالآتي : عرف من قبل (Yamaguchi , 2001) : إن نظام التداول الإلكتروني هو مجموعة كبيرة من الأنظمة المتعددة إذ يقدم خدمات متكاملة في مجال تبادل الأوراق المالية، فيبدأ بـ (توجيه وتسليم الأوامر من المستخدمين إلى النظام الذي ينفذ الأوامر ) الذي يقوم بنقل الأوامر إلى صفقات، والنشر الإلكتروني الذي يتم قبل التداول (بيع وشراء) ومعلومات بعد التداول (سعر الصفقة وكمية 
البيانات)، ويوفر للمتعاملين السرعة في التداول، تسهيل عملية اتصـال العملاء مع بعضهم، انخفاض التكاليف، انخفاض مخاطر

$$
\text { الإدارة، وحيادية موقع التداول. [1] }
$$

وعرف من قبل ( 2009, Jong \& Rindi) : هو عبارة عن مجموعة من الأوامر المفتوحة حيث يشكل هذا النظام شكل من أشكال نظام التداول البديل وتقوم أنظمة التداول الإلكتروني على جمع المشترين والبائعين معا لاكمال تنفيذ عمليات التداول الإلكتروني عن طريق أجهزة الحاسوب وشبكات الإنترنت الخاصة بالمستثمرين، ويكون هذا النظام مسجل وفق لائحة لجنة الأوراق المالية وسوق الأوراق المالية ويسمح هذا النظام بتنفيذ الأوامر بشكل كلي أو جزئي. [7] وعرف من قبل ( A. Hirt , 2012$)$ بصورة تلقائية إلكترونية وفق أسعار محددة، يمكن لنظام التداول عبر الإنترنت انتظار وصول أوامر البيع والثراء مطابقة، ويتيح نظام التداول عبر الإنترنت لمشتركيهم أن يطلعوا على دفاتر طلباتهم بصورة كاملة، والبعض يجعل دفاتر طلباتهم متاحة

$$
\text { على شبكة الإنترنت. [8] }
$$

وعرف من قبل (حمدون ، 2013): هو نظام يسمح للمستثر من إدارة استثمار اته في الأوراق المالية من خلال بيعها وشر اءها وتنفيذ الأو امر حيثما كان متو اجدا عن طريق شبكة الانترنت بالاشتر اك لدى شركة وساطة تكون مرخصة بمزاولة هذا النشاط.

وعرف من قبل (Nasdaq , 2013) هو مجمو عة بر امج منر ابطة ضمن قاعدة بيانات Dlatforms ) تعتمد تنفيذ أوامر البيع والثراء وفقا للقواعد السعرية المتطابقة بغض النظر عن كمية الأوامر المعروضة للبيع أو المطلوبة للشراء ، و الأساس هو التطابق السعري في تنفيذ الأمر بغض النظر عن وقت تسجيل أمر الثراء أو البيع ، مع قابلية إن ما تم شراؤه يمكن بيعه شرط تحقق التسوية المالية عليه وفقا لمحددات السوق [2] . مما تقلم يمكن تعريف نظام التداول الإكتروني: بأنه مجموعة برامج تقوم بتبويب معلومات الأور اق المالية وتنظيم قائمة أسعار لها، ليتم التعامل بها عن طريق المحطات الطرفية المرتبطة بها، من خلال المكاتب المتخصصة للقيام بعمليات البيع والثراء ومزاولة عمليات التداول بشكل إلكتروني بين المستثمرين، ويتميز هذا النظام بسرعة العمليات وإمكانية التسويات مباشرة و إعادة بيع ما تم شر اؤه بالإضافة إلى قدرة الإفصاح عن الأسعار و التنافس وفقا لقاعدة السعر في اكتساب الملكية. 1-3 أهداف نظام التّاول الإكتروني من أهداف نظام التداول الإكتروني في الأسواق المالية بشكل عام السعي لتحقيق هدفين أساسيين، على الرغم من اختلاف قو اعد التداول الإلكتروني فيها، هذه الأهداف جاءت كالآتي: 
1) توفير السيولة : المقصود بالسيولة (Liquidity) قدرة السوق المالية على تلبية متطلبات أوامر البيع من خلال أوامر الثراء، وكلما كانت سيولة الورقة المالية مرتفعة كانت مرونة السوق مرتفعة، وتعكس كفاءة آليات وقو اعد التداول و الإفصاح عن المعلومات. لذلك يعد جذب أكبر عدد ممكن من البائعين والمشترين وتوفير السيولة اللازمة هدفا مهما لأن للسوق قدرة على جذب كمية من الأوامر للسوق التي تقوم بالاعتماد على مدى وجود التزامات ثابتة من المتداولين فيه، أو على الأقل عدد منهم في سبيل توفير السيولة للسوق، حيث إن توفير السيولة في سوق محدد يثد جذب المتداولين الأخرين بإرسال الأوامر الخاصة بهم إلى هذه السوق وبالتالي يؤدي إلى زيادة سيولتها [10] و وإن للسيولة أثر على تكلفة عمليات التداول في أسواق الأوراق المالية، لذلك تعتبر عامل مهم في تحديد عمل الأسواق المالية وإدارة المحافظ فيها، وتعد أيضا عامل يقوم بحسم المنافسة بين أماكن التداول لتدفق الأوامر التي بصدرها المستثمرين كونها تؤثر على قرار المتداولين في السوق بخصوص مكان التداول. [11] و هنالك في الواقع ارتباط مشدد بين سيولة السوق وتكلفة عمليات التداول، حيث كلما كانت السوق ذات سيولة كبيرة يؤدي ذلك إلى خفض تكلفة التداول. إذ أن الزيادة في السيولة يدل على الزيادة من الكميات المعروضة و المطلوبة، وبالتالي المزيد من المنافسة التي تعمل على تو افر السيولة والتنافس في تتفيذ أسعار عادلة، وبالتالي يخفض من الفرق بين أفضل العروض و الطلبات، ويؤدي إلى تخفيض تكلفة التداول حيث يكون المتداول قادر على تنفيذ أمره مهما كان كبير ا وبسر عة وتكلفة

2) كذللك يهدف نظام التداول الإلكتروني على القيام بنفس الوظائف التي تقوم بها الأسواق التقليدية ولكن باستخدام تكنولوجيا المعلومات و الاتصالات الإكترونية المتطورة من أجل زيادة الكفاءة وخفض التكاليف. [12] 3) اكتشاف الأسعار (Discovery of prices): يعد اكتشاف أسعار الأوراق المالية خصوصا الافتتاح هدف أساسي للسوق المالية والتي تثشير إليها قواعد التداول الإلكتروني، لأنه جزء من كفاءة السوق من حيث القدرة على دمج المعلومات الحديثة للأوراق المالية التي تخص أسعارها ومركزها المالي وأحداثها الجوهرية بأقل وقت ممكن، وبالتالي يؤدي إلى تنفيذ أكبر حجم من الأوراق المالية من مستوى الأسعار السائد (الاستكثافي) حيث يقلل من احتمالية الغبن ويزيد من ثقة المتداولين بالسوق[3]. 4) يهدف إلى إظهار العرض والطلب للأوراق المالية بصورة علنية وتكون العروض مجهولة الهوية تعرض على شاثنات التداول الإلكترونية المتو اجدة في قاعات التداول حيث تكون هذه العروض متاحة لكافة المشتركين، حيث تنفذ المعاملات و عمليات التداول من دون معرفة كل من الطرفين لبعضهما. [13] 
مما تقدم يمكن القول بأن نظام التداول الإكتروني في الأسواق المالية يهدف إلى أن يوفر كافة سبل التسهيل و عنصر المرونة في إجراء عمليات التداول وتقديم أحدث طرق التداول إلى المتعاملين في الأسواق المالية مما يؤدي إلى زيادة قدرة الأسواق المالية على مواجهة التطورات السعرية في التداول و التطورات التكنولوجية الحديثة .

\section{4-1-1 مميزات وسلبيات نظام التّاول الإكتروني}

ساهمت التقنيات التكنولوجية وشبكات الاتصال الحديثة في تقليل التدخل البشري وكذلك تقليل تكاليف المعاملات، حيث تتميز تقنيات نظام التداول الإلكتروني بالسر عة في تنفيذ الصفقات وتسعى لزيادة الثفافية مقارنة بالأنظمة البدوية، وهناك عدد من [14]: خصاص أو مميزات نظام التداول الإلكتروني وكما يلي 1) تتميز عمليات نظام التداول الإكتروني بالسرعة القصوى عن طريق تتفيذ أوامر المستثرين وتسويتها مقارنة بالطرق الأخرى، إذ يستطيع المستثمر من خلال هذا النظام وفي أي مكان بالعالم التحقق من رصيده النقي، ورصيده من الأسهم، وكذلك ير اقب محفظته الاستنمارية وما يحدث عليها من تغييرات بالأرباح أو الخسائر، وله الحق في أن يضيف أو يعدل أو يلغي الأوامر الخاصة به وتنفيذها وتسوية المعاملات عن طريق تطبيقات النظام الإلكتروني من خلال جهاز الحاسوب أو الهاتف المحمول دون حاجته لزيارة السوق أو طلب الإعانة من الوسيط. 2) من طرق التداول الأخرى، حيث يتيح للمستثمرين تقديم طلب وعرض الأوراق المالية من أجل عملية التداول بكل

$$
\text { سهولة ويسر. [15] }
$$

إن التكلفة التي يقوم المستثمر بدفعها إلى الوسيط تكون منخفضة، لقاء تزويده بالخدمة الموكلة إليه .

إن لنظام التداول الإلكتروني أثز فعال في تحسين جودة عرض معلومات التداول وكافة الصفقات، ويتمتع بخاصية عدم الكثف عن هوية المتداولين.

يقضي نظام التداول الإلكتروني على الكثير من المشاكل التي تحصل في أسواق الأوراق المالية بين المستثرين و الوسطاء المتعلقة بعدالة التنفيذ.

6) إن تكاليف التداول التي يقوم بها المتداولين بالأسواق المالية تمثل نقطة مهمة بالنسبة إليهم، حيث إن التداول الإلكتروني يقلل من تكاليف التداول التي تمثل شيء رمزي وبالتالي يساعد المتداولين من جذب اهتماماتهم بشأن الأسو اق المالية واستثمار أمو الهم فيها ومزاولة الأنشطة المختلفة وذلك بسبب كفاءة الأسواق المالية [3] . 7حصل المستثمرون على المعلومات التي تخص الأوراق المالية التي ينم تداولها في الأسواق المالية بأي لحظة ليتم

اتخاذ القرار ات الاستثمارية المناسبة وفقا لقر ار حجم الاستثمار. 
8) يزيد من عدد المستتمرين وتزيد معدلات التداول للأسهم بالإضافة إلى جذب رؤوس الأموال الأجنبية وزيادة سيولة

$$
\text { السوق . }
$$

الثفافية في إتمام العمليات، حيث إن نظام التداول الإلكتروني يوفر بيانات ومعلومات قيمة عن العرض والطلب حيث

$$
\text { بإمكان المتداولين استخدام هذه المعلومات لوضع الاستر اتيجية الخاصة بهم. [16] }
$$

وفيما يتعلق بسلبيات نظام التداول الإكتروني من وجهة نظر المستثمر يتم حصر أهم السلبيات التي يعاني منها المستثمر كما

يلي : [17]

$$
\text { 1) الصعوبة في التو اصل مع الوسيط نتيجة الضعف في نظام الاتصالات في بعض الأحيان. }
$$

2) إهمال المعلومات والبيانات الحساسة والتي نكون مخزونة وذات الطابع السري من قبل الأفراد الذين يقومون

$$
\text { باستخدام نظم الحاسوب الآلي التي تخص المستثمر . }
$$

\section{المبحث الثاني \\ تحليل مؤشرات التذاول الإكتروني في سوق العراق للأوراق المالية}

للمدة (2018-2008)

\section{1-2-3 نشأة سوق العراق للأوراق المالية}

تم تأسيس سوق الأوراق المالية في العراق لأول مرة في تاريخه عام 1991 عندما تم تشريعه وفق القانون المرقم (24) لعام 1991 وأطلق عليه "سوق بغداد للأوراق المالية" نتيجة العديد من التحولات الهيكلية التي عاصرت الاقتصاد العراقي في منتصف الثمانينات وبداية التسعينات من القرن الماضي وكان السوق تابع إلى وزارة المالية العر اقية، وأدرجت فيه العديد من الشركات المختلطة والخاصة وفقا للقانون، وشرعت الكثير من القوانين والتشريعات الجديدة من أجل تنظيم المعاملات المالية و المصرفية والاستثمارية، مما ولّد حاجة مهمة لتأسيس سوق لتداول أسهم الثركات الخاضعة للأشر اف والمر اقبة على عمليات التداول والتبادل بين كافة الأطر اف في السوق ومراقبة الإدخار وتنمية وتطور الوعي الاستثماري لاى المشاركين في السوق وتوفير وسائل الحماية لاستثمار اتهم.

وباثر سوق بغداد للأور اق المالية عمله عام 1992 بقبول إدر اج (64) شركة مساهمة في السوق ونم عقدُ (6932) عقدَ تداول في السوق، وازدادت عدد الشركات المدرجة في السوق عام 2000 حيث بلغت (99) شركة مدرجة و(92020) عقد تنفيذي و(152) جلسة تداول، مما أدى إلى تتمية الاقتصاد العر اقي بصورة غير مباشرة، ونم إغلاق سوق بغداد للأوراق المالية بقرار

$$
\text { من مجلس إدارته 19/3/2003 بسبب ظروف الحرب. [18] }
$$


وتم تأسيس سوق العراق للأوراق المالية بموجب القانون المرقم (74) في 18/4/2004 و افتتح رسمبا في حزيران 2004 ، وقد أشار القانون المرقم (74) أن سوق العراق للأوراق المالية مؤسسة تنظيما ذاتيا مستقل إداريا وماليا لا يهدف إلى تحقيق الربح وتعود ملكيته للأعضاء المساهمين فيه ويخضع إلى رقابة هيئة الأوراق المالية. [5] 7-2-3 نشأة التداول الإكتروني في سوق العراق للأوراق المالية منذ عام 2004 لغاية نيسان 2009 كان سوق العراق للأوراق المالية يقوم بتنظيم عمليات التداول بالأوراق المالية عن طريق التداول اليدوي، ونظمت أول جلسة تداول في 24/6/2004 وإن التداول اليدوي هو عبارة عن تسجيل أوامر الثراء وأوامر البيع على لوحات بلاستيكية، ويبدأ التداول بأسهم الثركات حينما تتطابق أوامر البيع مع أوامر الثراء في السوق بين الأطر اف المتعاملة، وتتم عملية التسوية في اليوم التالي من عملية التداول وذلك وفقا لعقود نقل الملكية والتحويل التي تتم في مركز الإيداع العر اقي يدويا، وكان السوق يقوم بتنظيم عقد جلسات التداول اليدوي وينظم التداولات اليومية بثلاث جلسات أسبوعيا بالإضافة إلى الثركات المساهمة وشركات الوساطة والمستثرين و هيئة الأوراق المالية العر اقية، والثكل رقم (1) يوضح لوحة التداول اليدوي، وكان السوق يقوم جاهدا بفعالية ونشاط عاليين من أجل تحويل التداول اليدوي إلى التداول الإلكتروني عن طريق تطوير وتحديث آلياته التي تعد نوع جديد وغير مألوف في مجتمع الاستثمار بالأوراق المالية في العراق، وقد خطط لهذا النظام منذ عام 2007 واعتبر مشروع تحت الإنجاز، حتى 19/4/2009 تم تطبيق التداول الإلكتروني في سوق العراق Horizon \& للأوراق المالية، حيث تم إطلاق وتنظيم أول جلسة تداول بآلية النظم الإلكترونية من خلال استخدام نظام الذي يمثل الترابط والاندماج والمحاكاة بين نظام التداول OMX Technology المصدر من شركة Equator ونظام الإيداع (Equator) و الذي يتم نطبيقه في أغلب البورصات العربية وعدد من البورصات العالمية (التقرير السنوي ،2009 ; 8)، وفي عام 2012 أجريت در اسة وتحليل التداول الإلكتروني الذي تم اقتر احه من قبل Nasdaq OMX الذي يتم استخدامه في البورصات العربية والعالمية ويطلق على هذا النظام نظام "X-STREAM" ودراسة مدى أهيته في زيادة فعالية الأنشطة في سوق العراق للأوراق المالية (التقرير السنوي ، 2012 ; 7)، ونم تحديث وتطبيق نظام التداول الإلكتروني من نظام (Horizon) إلى نظام التداول الحديث (X-STREAM) إذ نم البدأ بتنفيذ المشروع فعليا في 1/7/2013 ونم إطلاقه في 26/10/2014 وفق الخطة التي وضعت للمشروع وبقرار من مجلس المحافظين والدعم من قبل Nasdaq OMX ويعد هذا المشروع من أهم و أضخم الأنظمة و المشاريع التي تم تنفيذها في سوق العراق للأوراق المالية منذ عام 2009 [6]. 
ARID International Journal of Social Sciences and Humanities (AIJSSH) VOL.2, Special Issue (1), August 2020

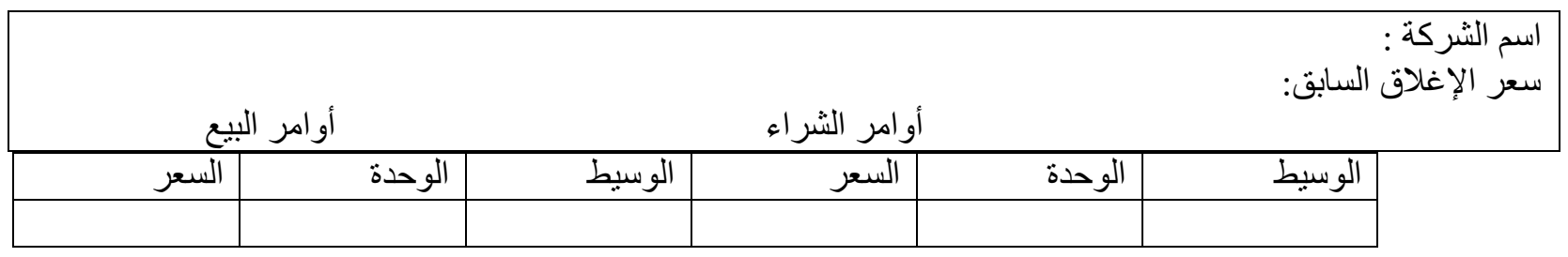

شكل (1): لوحة التداول بالأوراق المالية ـ آلية التداول اليدوي

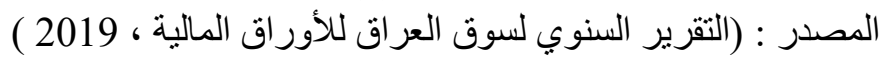

8-2-3 مؤشرات التداول في سوق العراق للأوراق المالية

$$
\text { أولا - عدد الأسهم المتداولة (حجم التداول) }
$$

يعد عدد الأسهم المتداولة أحد المؤشرات المعتمدة في أسواق الأوراق المالية، ويعطي دلالة على حجم الطلب أو العرض أو كليهما معا ويقود إلى استنتاج وتوقع سعر الورقة المالية. فعندما يكون الطلب أكبر تتحرك الأسعار نحو الارتفاع سواء التدريجي أم المندفع والعكس صحيح عندما يكون المعروض للورقة المالية أكبر من الطلب عليها، والتي غالبا ما تكون بسبب عوامل لها علاقة باجتماعات الهيئات العامة ونوقع توزيع الأرباح. ويوضح الجدول رقم (1) عدد الأسهم المنداولة للسنة (2008) - 2018) في سوق العراق للأوراق المالية.

$$
\text { جدول (1): عدد الأسهم المتداولة (حجم التداول) في سوق العر اق للأور اق المالية للمدة (2008 - 2018) }
$$

\begin{tabular}{|c|c|c|c|}
\hline معدل الجلسة الو احدة لعدد & نسبة التغير (\%)3 & 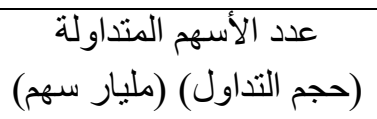 & السنة \\
\hline 1.08 & - & 151 & 2008 \\
\hline 1.38 & $40 \%$ & 211 & 2009 \\
\hline 1.07 & $21 \%$ & 255 & 2010 \\
\hline 2.12 & $92 \%$ & 492 & 2011 \\
\hline 2.72 & $27 \%$ & 626 & 2012 \\
\hline 3.79 & $40 \%$ & 876 & 2013 \\
\hline 3.28 & $-14.8 \%$ & 746 & 2014 \\
\hline 2.65 & $-17.02 \%$ & 619 & 2015 \\
\hline 4.43 & $67.7 \%$ & 1038 & 2016 \\
\hline 5.08 & $17.05 \%$ & 1215 & 2017 \\
\hline 3.49 & $-31.5 \%$ & 832 & 2018 \\
\hline
\end{tabular}


المصدر : من إعداد الباحثة بالاعتماد على بيانات التقارير السنوية لسوق العراق للأوراق المالية من (2008 - 2018) . نلاحظ من خلال بيانات جدول رقم (1) تباين عدد الأسهم المتداولة (حجم التداول) في سوق العراق للأوراق المالية خلال سنوات الدراسة، ففي عام 2008 بلغ عدد الأسهم المنداولة (151) مليار سهم حيث تراجع عن عام 2007 بنسبة 1.4\% - يعود سبب هذا الانخفاض بسبب حدوث الأزمة المالية العالمية وتأثير ها على السوق حيث كان معدل الجلسة الواحدة للتداول 1.08 ، وفي عام 2009 ارتفع عدد الأسهم المنداولة إلى (211) مليار سهم وبنسبة ارتفاع 40\% حيث كان التداول نوعين خلال عام 2009 التداول اليدوي بلغ (105) مليار سهم والتداول الإلكتروني بلغ (106) مليار سهم بمعدل 1.38 للجلسة الواحدة، وكان سبب نأثير هذه الزيادة هو تحويل نظام التداول اليدوي إلى نظام التداول الإلكثروني في عام 2009 مما أدى إلى زيادة عمليات التداول في السوق و إقبال مستثمرين جدد، وبلغ عدد الأسهم المتداولة في عام 2010 (255) مليار سهم وبنسبة ارتفاع بلغت $21 \%$ عن عام 2009 وذللك نتيجة تم تشكيل حكومة جديدة في ذلك العام مما يساعد على استتباب الأمن و العمل على تطوير البيئة الاستثمارية في البلاد بمعدل 1.07 للجلسة الواحدة، وارتفع عدد الأسهم المتداولة في سوق العراق للأوراق المالية بنسبة 92\% في عام 2011 أي بمقدار (492) مليار سهم وبمعدل 2.12 للجلسة الواحدة وذللك لنشر وتوعية المستثرين بالثقافة الاستثمارية في السوق ونتيجة تطوير التقنيات الإلكترونية الخاصة بعمليات التداول، وفي عام 2012 استمر ارتفاع عدد الأسهم المتداولة حيث بلغ (626) مليار سهم وبنسبة ارتفاع 27\%، استمر الارتفاع في عدد الأسهم المتداولة في سوق العراق للأوراق المالية للسنو ات اللاحقة وانخفض في عام 2015 نتيجة التأثر بنتائج الأزمة المالية العالمية مما أثر على الوضع الاقتصـادي في البلاد بسبب انخفاض أسعار النفط على مستوى العالم منذ عام 2014 حيث بلغ عدد الأسهم المتداولة في سوق العراق للأوراق المالية (616) مليار سهم وبنسبة انخفاض بلغت 17.02\%- بمعل 2.65 للجلسة الواحدة، ثم ارتفع عدد الأسهم المنداولة في السوق ارتفاع كبير عام 2016 حيث بلغ (1038) مليار سهم وبنسبة تغير 67.7\% وبمعدل 3.43 للجلة الواحدة نتيجة العمل على تطوير التقنيات الإلكترونية في السوق ونشر الثقافة الاستثارية بين المستثرين في السوق و إلى جانب الثفافية والافصـاح في إدارة العمليات في السوق، واستمر الارتفاع في عدد الأسهم المتداولة حيث بلغ عام 2017 (1215) مليار سهم وبنسبة ارتفاع 17.05\% وتعتبر أعلى السنوات من ناحية عدد الأسهم المتداولة خلال سنوات الدراسة، وذللك بسبب الأنظمة التنظيمية الجيدة و القو اعد الموضو عة من قبل إدارة السوق، مما أدى إلى السرعة والسهولة في إتمام عمليات البيع والثراء في السوق وجذب مستثرين جدد إلى السوق نتيجة السماح للأجانب بالاستثمار في عدد من القطاعات في سوق العر اق للأوراق المالية و هذا بالتالي من العوامل التي ساعدت على زيادة عدد الأسهم المتداولة في سوق العراق للأوراق المالية، وفي عام 2018 انخفض عدد الأسهم المتداولة في سوق العراق للأوراق المالية نتيجة انخفاض ثقة المستثمرين و المساهمين في السوق بسبب أن 
هناك (35) شركة مساهمة تأخرت في تقديم الإفصاح السنوي لعملياتها حيث بلغ عدد الأسهم المتداولة في السوق (832) مليار

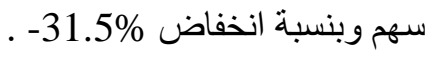
ثانيا - قيمة الأسهم المتداولة (قيمة التداول) تؤثر قيمة الورقة المالية بالإضافة إلى عدد الأسهم المتداولة في تحديد القيمة الكلية للأوراق المالية المتداولة لذلك يعد هذا المؤشر ثاني أهم مؤشر في أسواق الأوراق المالية . ويوضح الجدول رقم (2) الأرقام الكلية للأوراق المالية للمدة (2008 - 2018) . جدول (2): قيمة الأسهم المتداولة (قيمة التداول) في سوق العراق للأوراق المالية للمدة (2008 - 2018)

\begin{tabular}{|c|c|c|c|}
\hline معدل الجلسة الواحدة لقيمة الأسهم & نسبة التغير (\%) & 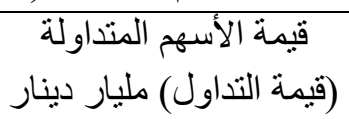 & السنة \\
\hline 2.16 & - & 301 & 2008 \\
\hline 2.70 & $36 \%$ & 411 & 2009 \\
\hline 1.68 & $-2.81 \%$ & 400 & 2010 \\
\hline 2.11 & $135 \%$ & 941 & 2011 \\
\hline 3.88 & $5 \%$ & 894 & 2012 \\
\hline 12.31 & $218 \%$ & 2845 & 2013 \\
\hline 3.96 & $-68.3 \%$ & 901 & 2014 \\
\hline 2.12 & $-45.06 \%$ & 495 & 2015 \\
\hline 2.20 & $4.2 \%$ & 516 & 2016 \\
\hline 3.76 & $74.4 \%$ & 900 & 2017 \\
\hline 1.95 & $-48.2 \%$ & 466 & 2018 \\
\hline
\end{tabular}

من خلال جدول رقم (2) نلاحظ أن قيمة الأسهم المتداولة (قيمة التداول) في سوق العراق للأوراق المالية خلال سنوات الدر اسة تتذبذب بالارتفاع و الانخفاض وفقا للتغيرات التي يتعرض لها السوق، ففي عام 2008 بلغت (301) مليار دينار بنسبة انخفاض 29.5\%- مقارنة بعام 2007 إذ بلغت قيمة الأسهم المتداولة (427) مليار دينار وكان معدل الجلسة الواحدة للتداول 2.16، وذللك نتيجة تأثر السوق بالأزمة المالية العالمية التي أثرت على معظم الأسواق المالية العربية والعالمية مما أدى إلى هبوط معظم مؤشرات التداول في الأسواق، ارتفعت قيمة الأسهم المتداولة (قيمة التداول) في سوق العر اق للأوراق المالية عام 2009 حيث بلغت (411) مليار دينار بنسبة تغير 36\% تضمنت جزئيين من عمليات التداول الجزء الأول التداول اليدوي حيث بلغ (225) مليار دينار والجزء الثاني التداول الإلكتروني بلغ (186) مليار دينار بمعدل 2.70 للجلسة الواحدة، وذلك وفقا 
لاستحداث آلية التداول في السوق بنظام (horizon) مما أدى إلى رفع نسب المؤشرات في السوق، وفي عام 2010 انخفضت قيمة الأسهم المتداولة (قيمة التداول) إلى (400) مليار عر اقي وبنسبة تغير 2.81\%- بمعدل 1.68 للجلسة الواحدة نتيجة عقبات آثار الأزمة المالية العالمية، وعاود الارتفاع في قيمة الأسهم المتداولة عام 2011 نتيجة التطور التقني والوظيفي في السوق ونشر الوعي الاستثماري بين المستثمرين مما ساعد على جذب استثمارات عديدة في السوق اذ بلغت قيمة الأسهم المتداولة (قيمة التداول) (941) مليار دينار بنسبة ارتفاع 135\% بمعدل تداول 2.11 للجلسة الواحدة، و انخفضت قيمة الأسهم المتداولة عام 2012 إذ بلغت (894) مليار دينار وبنسبة تغير 5\%- بمعدل تداول 3.88 للجلسة الواحدة، وارتفعت قيمة الأسهم المتذاولة بأعلى نسبة بالنسبة لسنو ات الدر اسة حيث بلغت عام 2013 (2845) مليار دينار وبنسبة 218\% حيث بلغ معدل التداول للجلسة الواحدة 12.31 نتيجة نطوير الأنظمة ونشر ثقافة الاستثمار في سوق العراق للأوراق المالية، واستمرت حالة التذبذب بين الارتفاع والانخفاض بقيمة الأسهم المتداولة للسنوات التالية حيث بلغت عام 2014 (901) مليار دينار وبنسبة انخفاض 68.3\% وبمعدل تداول 3.96 وفي عام 2015 (495) مليار دينار بنسبة تغير 45.06\%- وبمعدل تداول 2.12 للجلسة الواحدة وفي عام 2016 (516) مليار دينار وبنسبة ارتفاع 4.2\% بمعدل تداول 2.20 للجلسة الواحدة، وذلك بسبب الأوضاع الاقتصادية والبيئية التي تحيط بالسوق، وارتفعت قيمة التداول عام 2017 حيث بلغت (900) مليار دينار وبنسبة تغير 74.4\% وبمعدل تداول 3.76 للجلسة الواحدة نتيجة عمليات الإفصاح والثفافية التي يمارسها السوق في عملياته، وانخفضت قيمة التداول عام 2018 حيث بلغت (466) مليار دينار وبنسبة 48.2\%- بمعدل تداول 1.95 للجلسة الواحدة، حيث كانت سياسة جذب الاستثمار ضعيفة في السوق نتيجة عدم تحليل ودر اسة تنمية قطاع الأوراق المالية في السوق و عدم دراسة القيمة الحقيقية للسهر ومقارنتها بالقيمة السوقية ونتيجة ضعف التو اصل مع المساهمين و المستثمرين . ثالثا - عدد العقود المنفذة

يعتبر عدد العقود المنفذة مؤشر تحليل أداء التداول بالأور اق المالية و هناك عدة فرضيات مصاحبة لهذا المؤشر وهي : 1- ارتفاع القيمة وارتفاع العقود يدل على أن معدل الدوران مرتفع وأن صغار ومتوسطي المستثرين هم الفئة الأكبر في التداول.

2- ارتفاع القيمة وانخفاض العقود يدل على انخفاض معدل الدوران وأن كبار المستثمرين هم من يؤثر في التداول . 3- انخفاض القيمة وارتفاع العقود يدل على أن معدل دوران الأسهم مرتفع لكن هناك انخفاض في أسعار الأوراق المالية 4- انخفاض القيمة و انخفاض العقود يدل على أن التداول غير كفوء ويعاني من ركود ـ. 
جدول(3): عدد العقود المنفذة في سوق العراق للأوراق المالية للمدة (2008 - 2018)

\begin{tabular}{|c|c|c|c|}
\hline معدل الجلسة الواحدة لعدد العقود & نسبة التغير(\%) & عدد العقود المنفذة (عقد) & السنة \\
\hline 223.7 & - & 31108 & 2008 \\
\hline 324.5 & $58.6 \%$ & 49339 & 2009 \\
\hline 302.6 & $45.37 \%$ & 71722 & 2010 \\
\hline 571.4 & $85 \%$ & 132574 & 2011 \\
\hline 591.4 & $2.6 \%$ & 136039 & 2012 \\
\hline 547.9 & $-7 \%$ & 126094 & 2013 \\
\hline 462.2 & $-17.3 \%$ & 104938 & 2014 \\
\hline 519.2 & $15.2 \%$ & 120978 & 2015 \\
\hline 479.6 & $-7.2 \%$ & 112230 & 2016 \\
\hline 400.8 & $-14.6 \%$ & 95806 & 2017 \\
\hline 382.6 & $-5 \%$ & 91067 & 2018 \\
\hline
\end{tabular}

المصدر : من إعداد الباحثة بالاعتماد على بيانات التقارير السنوية لسوق العر اق للأوراق المالية للمدة (2008 - 2018) نلاحظ من خلال الجدول رقم (3) إن عدد العقود المنفذة في سوق العراق للأوراق المالية يتراوح ما بين الارتفاع والانخفاض وفقا لما يواجه السوق من ظروف وأزمات تحيط به ففي عام 2008 بلغ عدد العقود المنفذة في السوق (31108) عقد وبنسبة ارتفاع 0.7\% مقارنة بعام 2007 حيث بلغ عدد العقود المنفذة (30825) عقد وبمعدل تداول 223.7 للجلسة الواحدة، على الرغم من تأثر السوق بالأزمة المالية العالمية إلا أن إبر ام العقود استمر وفقا للعمليات التنظيمية المتو اجدة في السوق، وفي عام 2009 ازداد عدد العقود المنفذة في السوق نتيجة تطوير أنظمة التداول وزيادة عدد المستثرين المتواجدين في السوق حيث بلغ عدد العقود المنفذة (49339) عقد وبنسبة 58.6\% بمعدل تداول بلغ 324.5 للجلسة الواحدة، واستمر عدد العقود المنفذة بالارتفاع للسنو ات اللاحقة حيث بلغ عام 2010 (71722) عقد وبنسبة 45.37\% بمعدل تداول 302.6 للجلسة الواحدة نتيجة تعزيز بدأ الاستثمار ات الجديدة والتشريعات والقو انين في البنية الأساسية لنمو البلاد، وارتفع عدد العقود المنفذة ارتفاعا كبير ا عام 2011 حيث بلغ (132574) عقد وبنسبة 85\% بمعدل تداول 571.4 للجلسة الواحدة وفقا للبيانات والمعلومات و عمليات الإفصاح في السوق وتظوير الأنظمة في السوق التي ساعدت على ارتفاع المؤشرات، واستمر الارتفاع في عدد العقود المنفذة في سوق العر اق للأوراق المالية للسنوات اللاحقة حنى بلغ عام 2016 (112230) عقد وبنسبة 7.2\%- بمعدل تداول 479.6 للجلسة الواحدة، وبدأ بالتراجع منذ عام 2017 على الرغم من نشاط التداول الفعال في السوق ومواكبة التطور في آليات التداول إلا أن السبب يعود لرغبات واحتياجات المستثمرين من العقود، حيث بلغ عدد العقود المنفذة (95806) بنسبة انخفاض - 
14.6\% وبمعدل نداول للجلسة الواحدة منخفض أيضا اذ بلغ 400.8، وانخفض عام 2018 بنسبة 5\%- حيث بلغ عدد العقود المنفذة في السوق (91067) عقد بمعد تداول 382.6 للجلسة الو احدة نتيجة ضعف ثقة المستثمرين و المساهمين بالسوق .

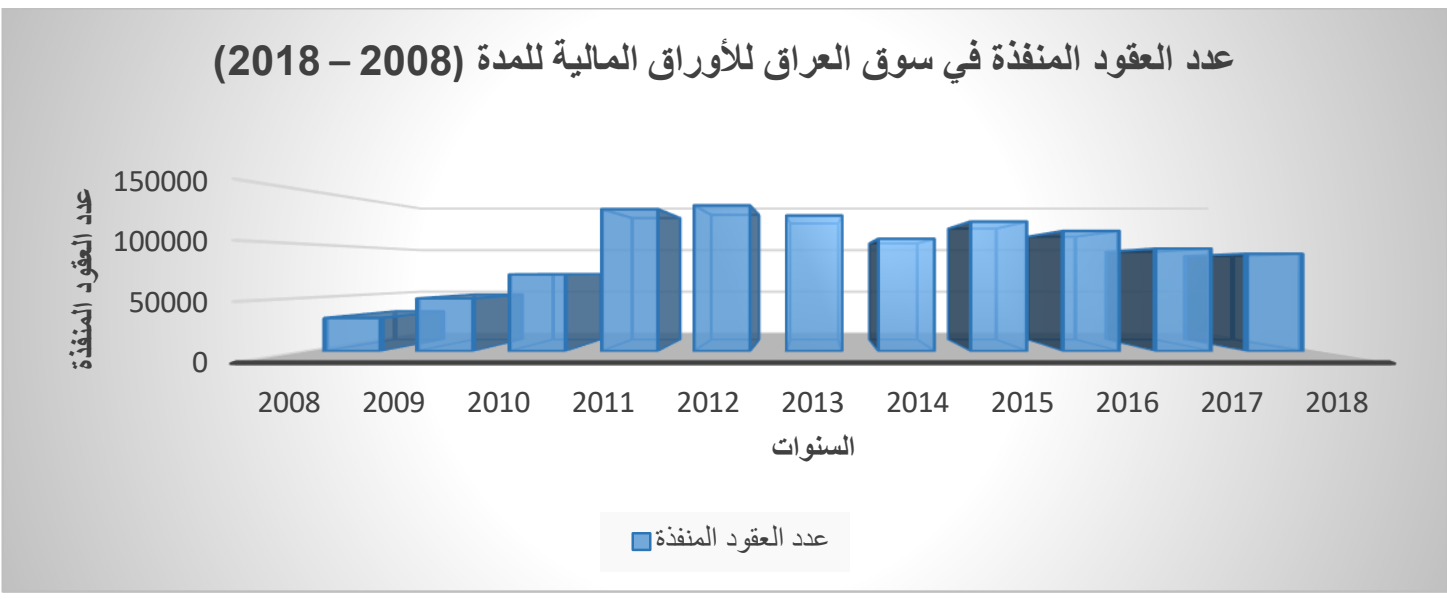

$$
\text { شكل (4): عدد العقود المنفذة في سوق العراق للأوراق المالية للمدة (2008 - 2018) }
$$

المصدر : من اعداد الباحثة بالاعتماد على بيانات جدول رقم (3) ، و الموضح فيه عدد العقود المنفذة في سوق العراق للأوراق

يوضح شكل رقم (4) إن عدد العقود المنفذة في سوق العراق للأوراق المالية، تتجه نحو التزايد سنة تلو أخرى نتيجة عمليات

$$
\text { رابداول التي تتم في السوق وساعد بهذه الزيادة نظام التداول الإلكتروني المتبع في السوق . }
$$

بعتبر من المؤشرات التي ييحث عنها المستثر عند الإقدام على الدخول في أي سوق للأوراق المالية خصوصا صناديق الاستثمار الأجنبية كونها تعطي انطباعا على حجم السوق والقدرة على توفبر السيولة اللازمة للتأثثر في كل ورقة مالية، لذلك فأن الأسواق الناشئة تتراوح القيمة السوقية لها بين 10 مليار \$ إلى 100 مليار \$ . و القيمة السوقية = مجموع رؤوس أموال الشركات × سعر الإغلاق السنوي ويبحث المستثمر عادة على رأس المال الحر غير المقيد مضروبا في سعر الإغلاق السنوي لمعرفة مدى التأثثر أو القدرة على النأثير عند شراء وبيع الورقة المالية . 
جدول(4): القيمة السوقية في سوق العراق للأوراق المالية للمدة (2008 - 2018)

\begin{tabular}{|c|c|c|}
\hline نسبة التغير (\%) & القيمة السوقية (مليار دينار ) & السنة \\
\hline- & 2283 & 2008 \\
\hline $36.8 \%$ & 3125 & 2009 \\
\hline $10.26 \%$ & 3446 & 2010 \\
\hline $43 \%$ & 4930 & 2011 \\
\hline $13.5 \%$ & 5597 & 2012 \\
\hline $105 \%$ & 11476 & 2013 \\
\hline$-16.8 \%$ & 9546 & 2014 \\
\hline$-2.9 \%$ & 9265 & 2015 \\
\hline $0.9 \%$ & 9355 & 2016 \\
\hline $14.6 \%$ & 10721 & 2017 \\
\hline $5.9 \%$ & 11350 & 2018 \\
\hline
\end{tabular}

المصدر : من إعداد الباحثة بالاعتماد على بيانات التقارير السنوية لسوق العراق للأوراق المالية للمدة (2008 - 2018) . من خلال بيانات جدول رقم (4) نلاحظ أن مؤشر القيمة السوقية في سوق العراق للأوراق المالية يتسم بالتفاوت خلال سنوات الدر اسة، ففي عام 2008 ارتفعت القيمة السوقية بنسبة 7.2\% مقارنة بعام 2007 حيث بلغت (2283) مليار دينار، بالر غم من حدوث الأزمة المالية العالمية وتأثثير ها على معظم الأسو اق المالية العربية والعالمية، وبلغت القيمة السوقية عام 2009 (3125) مليار دينار بنسبة ارتفاع 36.8\% مقارنة بعام 2008 جاءت هذه الزيادة وفقا للتطورات الحديثة في عمليات التداول والإدارة التنظيمية في السوق، واستمرت القيمة السوقية بتسجيل ارتفاع ملحوظا للسنوات اللاحقة وذلك وفقا لعدد من العوامل التي ساهدت بتصاعد القيمة السوقية في السوق منها تحسن الوضع الأمني في البلاد، تحديث نظام التداول الإلكتروني، دخول قطاع جديد إلى السوق عام 2013 وهو قطاع الاتصالات من حيث تفاوتت القيمة السوقية بالارتفاع على مدى هذه السنوات حيث تراوحت ما بين (3446) مليار دينار إلى (11476) مليار دينار، وفي عام 2014 انخفضت القيمة السوقية في سوق العراق للأوراق المالية وفقا للأوضاع الأمنية و السياسية التي شهدها البلد وتأثثر ها على الاقتصاد بصورة عامة وعلى سوق العراق للأوراق المالية بصورة خاصة،، حيث بلغت (9546) مليار دينار وبنسبة تغيير 16.8\%- ، و استمرت بالانخفاض حتى نهاية عام 2015 حيث بلغت القيمة السوقية (9265) مليار دينار وبنسبة انخفاض 2.9\%- وذلك وفقا للأوضاع السياسية و الاقتصادية المتوترة التي شهدتها البلاد، وارتفعت القيمة السوقية ارتفاع نسب عام 2016 حيث بلغت (9355) مليار دينار وبنسبة تغيير 0.9\% ، وذلك نتيجة تطوير الأنظمة في السوق ونشر ثقافة الاستثمار والتداول بالأوراق المالية، وارتفعت القيمة السوقية في سوق العراق للأوراق المالية عام 2017 حيث بلغت (10721) مليار دينار وبنسبة 14.6\% نتيجة نطوير الأنظمة القانونية و الإدارية وتنتيط حركة التداول من خلال الأنظمة الحديثة المستخدمة في السوق، وبلغت القيمة السوقية للأسهم المدرجة في سوق العر اق للأوراق المالية عام 2018 (11350) مليار دينار وبنسبة 5.9\% . 
ومن ربط المؤشرات وتحليلها وفقا للعلاقة بين مؤشرات عدد الأسهم المتداولة وقيمة الأسهم المتداولة وعدد العقود المنفذة و القيمة السوقية، نجد أن التداول في سوق العراق للأوراق المالية يميل إلى أن يكون سوقا لصغار ومتوسطي المستثمرين خلال المدة (2008 - 2015) ، وسوق لكبار المستثمرين للمدة (2016 - 2018) .

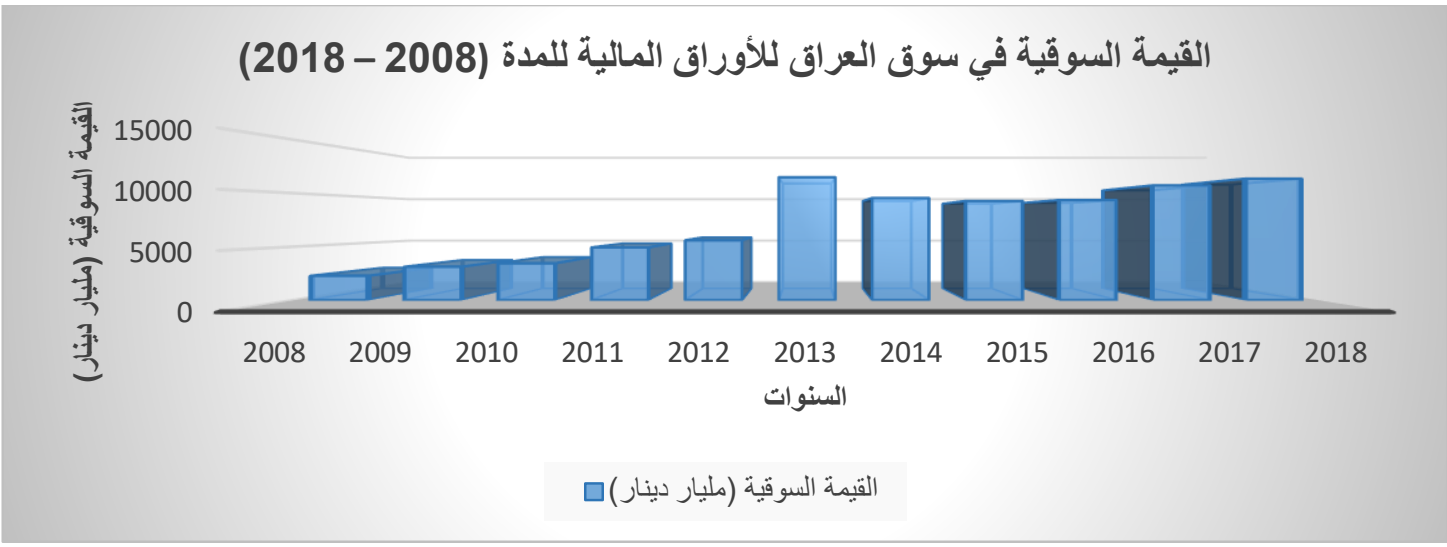

شكل(5): القيمة السوقية في سوق العراق للأوراق المالية للمدة (2008 - 2018)

المصدر : من إعداد الباحثة بالاعنماد على بيانات جدول رقم (4) المبين فيه القيمة السوقية في سوق العر اق للأور اق المالية. يوضح شكل رقم (5) إن القيمة السوقية تتصاعد في سوق العراق للأوراق المالية خلال سنوات الدر اسة، مما يظهر بأن للتداول الإلكتروني نأثنير ا كبير ا على السوق ويرفع من كفاءته . خامسا - عدد الثركات المدرجة و المتداولة

يوفر عدد الثركات المدرجة رؤية في اهتمام الثركات القائمة على الإدراج من حجم الاقتصاد الوطني من خلال تمثيل الثركات المختلطة والخاصة والقطاع الخاص مقارنة مع حجم الناتج المحلي الإجمالي كما إن عدد الشركات المتداولة تعطي انطباعا لنوع الملكية ومدى اقتر ابها من أن تكون حرة أم إنها شركة مساهمة عائلية أم مسيطر عليها أشخاص متحالفين فكلما زاد معدل دوران الأسهم أعطى دلالة على أن الثركات غير عائلية ولا يسيطر عليها أشخاص متحالفين . ويوضح الجدول رقم (5) عدد الثركات المدرجة والمتداولة للمدة (2008 - 2018) في سوق العراق للأوراق المالية . 
جدول(5): عدد الثركات المدرجة والمتداولة في سوق العر اق للأور اق المالية للمدة (2008 - 2018)

\begin{tabular}{|c|c|c|c|c|}
\hline نسبة التغير (\%) & عدد الثركات المتداولة & نسبة التغير (\%) & عدد الشركات المدرجة & السنة \\
\hline- & 87 & - & 94 & 2008 \\
\hline $2.2 \%$ & 89 & $-3.1 \%$ & 91 & 2009 \\
\hline$-6.74 \%$ & 83 & $-6.59 \%$ & 85 & 2010 \\
\hline- & 83 & $2 \%$ & 87 & 2011 \\
\hline$-3.6 \%$ & 80 & $-2.3 \%$ & 85 & 2012 \\
\hline$-1 \%$ & 79 & $-2 \%$ & 83 & 2013 \\
\hline$-1.2 \%$ & 78 & - & 83 & 2014 \\
\hline $5.1 \%$ & 82 & $18 \%$ & 98 & 2015 \\
\hline$-8.5 \%$ & 75 & $-1 \%$ & 97 & 2016 \\
\hline $17.3 \%$ & 88 & $4.1 \%$ & 101 & 2017 \\
\hline$-11.4 \%$ & 78 & $3 \%$ & 104 & 2018 \\
\hline
\end{tabular}

المصدر : من إعداد الباحثة بالاعتماد على بيانات التقارير السنوية لسوق العر اق للأوراق المالية للمدة (2008 - 2018) . من خلال الجدول أعلاه نلاحظ أن عدد الثركات المدرجة والمتداولة في سوق العراق للأوراق المالية تتذبذب خلال سنوات الدراسة، ففي عام 2008 بلغت عدد الشركات المدرجة في سوق العراق للأوراق المالية (94) شركة منها (87) شركة متداولة في السوق مقارنة بعام 2007 حيث قدرت الثركات المتداولة بنسبة 2.4\% ، وفي عام 2009 انخفضت عدد الثركات المدرجة في السوق حيث بلغت (91) شركة وبنسبة نغيير 3.1\%- منها (89) شركة منداولة مقارنة بعام 2008 على الرغم من استحداث آلية التداول في السوق إلا أنه سبب تخوف من قبل الثركات فيما إذا كانوا سوف يحققون معدل تداول أعلى أم لا، استمرت الثركات المدرجة بالانخفاض في السوق حيث بلغت الثركات المدرجة عام 2010 (85) شركة وبنسبة تغير 6.59\% وبلغت الثركات المتداولة (83) شركة وبنسبة 6.74\%- نتيجة الأوضاع السياسية المتدهورة في البلد، وفي عام 2011 ارتفعت عدد الثركات المدرجة في سوق العراق للأوراق المالية حيث بلغت (87) شركة وبنسبة ارتفاع 2\% ومنها (83) شركة متداولة وبدون تغير عن عام 2010، ثم عاود الانخفاض في الثركات المدرجة في السوق للسنوات اللاحقة بسبب الأوضاع الأمنية والاقتصادية في البلد حتى عام 2015 حيث بلغت الثركات المدرجة أسهمها في السوق (98) شركة وبنسبة تغيير 18\% وتم تداول اسهم (82) شركة في السوق بنسبة 5.1\% على الرغم من الاضطر ابات والأوضاع التي شهدها البلد في ذللك العام، وفي عام 2016 انخفضت عدد الشركات المدرجة إلى (97) شركة في السوق وبنسبة انخفاض بلغت 1\%- وتم تداول أسهم (75) شركة وبنسبة تغيير 8.5\%- ، وارتفعت عدد الثركات المدرجة في السوق عام 2017 إلى (101) شركة وبنسبة 4.1\% وتم تداول أسهم (88) شركة وبنسبة 17.3\% ونلك وفقا للسماح لمستثرين أجانب بالاستثمار في سوق العراق للأور اق المالية للتطور ات التكنولوجية والوظيفية في السوق، وفي عام 2018 ارتفعت عدد الثركات المتداولة في سوق العراق 
للأوراق المالية حيث بلغت (104) شركة وبنسبة تغير 3\% وبلغت أسهم الشركات المتداولة في السوق (78) شركة وبنسبة ـ

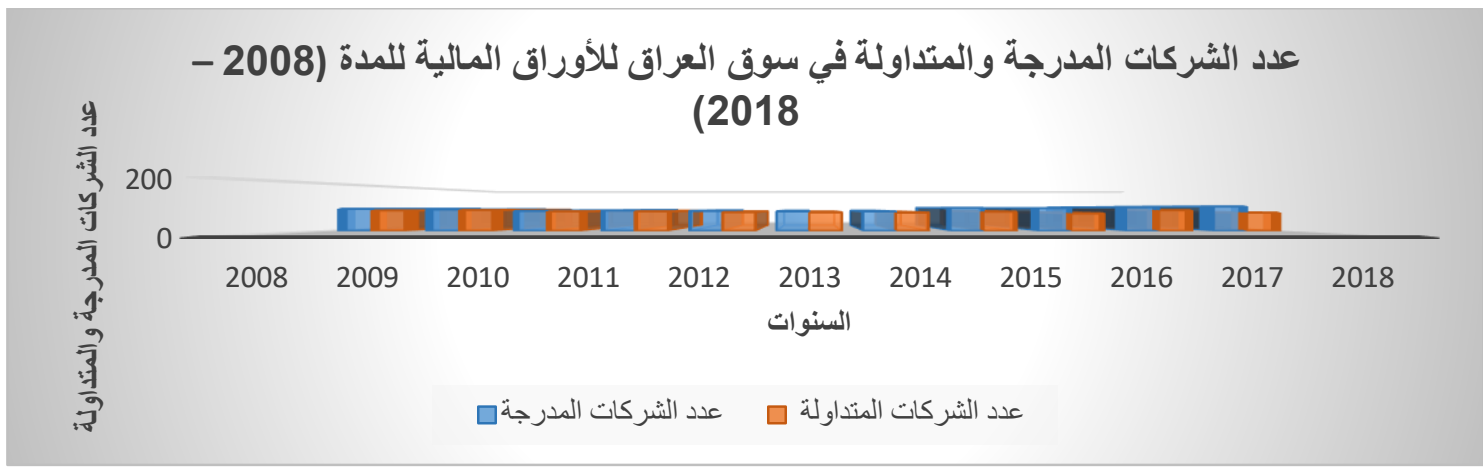

شكل(6): عدد الشركات المدرجة و المتداولة في سوق العراق للأوراق المالية للمدة (2008 - 2018)

المصدر : من إعداد الباحثة بالاعنماد على بيانات جدول رقم (5) و الموضح فيه عدد الثركات المدرجة والمتداولة في سوق

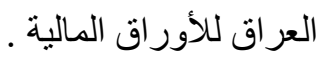
يوضح شكل رقم (6) إن عدد الثركات المدرجة والمتداولة تتز ايد في السوق وفقا لعمليات التداول الكبيرة في سوق العراق للأوراق المالية واتباع نظام التداول الإلكتروني الذي اكتسب السوق من خلاله ثقة المستثمرين نتيجة توفير عمليات النظام والأمان المنوفرة في السوق .

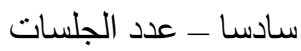

يمثل عدد الجلسات التي ينظمها السوق مؤشر استقرار للتداول إذ نجح السوق في تنظيم أعلى عدد من الجلسات سنويا اعتبار ا من عام (2010) بعد استقرار استخدام أنظمة التداول الإلكتروني والإيداع المركزي عام (2009) جدول(6): عدد الجلسات التي عقدت في سوق العراق للأوراق المالية للمدة (2008 - 2018)

\begin{tabular}{|c|c|c|}
\hline نسبة التغير (\%) & (السن| \\
\hline- & 139 & 2008 \\
\hline $9.3 \%$ & 152 & 2009 \\
\hline $55.92 \%$ & 237 & 2010 \\
\hline$-2.1 \%$ & 232 & 2011 \\
\hline$-0.8 \%$ & 230 & 2012 \\
\hline $0.43 \%$ & 231 & 2013 \\
\hline$-1.7 \%$ & 227 & 2014 \\
\hline $2.6 \%$ & 233 & 2015 \\
\hline $0.4 \%$ & 234 & 2016 \\
\hline $2.1 \%$ & 239 & 2017 \\
\hline$-0.4 \%$ & 238 & 2018 \\
\hline
\end{tabular}


المصدر : من إعداد الباحثة بالاعتماد على بيانات التقارير السنوية لسوق العراق للأوراق المالية للمدة (2008 - 2018) . من خلال جدول رقم (6) نلاحظ أن عدد الجلسات التي عقدت في سوق العراق للأوراق المالية تتراوح ما بين الارتفاع و الانخفاض خلال سنوات الدر اسة، ففي عام 2008 بلغت عدد الجلسات التي عقدت في السوق (39) جلسة تداول وبنسبة تغير عن عام 2007 17\% ، حيث تم عقد الجلسات بمعدل ثلاث جلسات أسبو عيا، وفي عام 2009 بلغت عدد الجلسات التي عقدت في السوق (152) جلسة حيث كان منها (61) جلسة تداول تمت بواسطة التداول اليدوي و (106) جلسة تداول تمت بواسطة التداول الإلكتروني، حيث ارتفعت عدد الجلسات بنسبة 9.3\% نتيجة نظور آلية التداول وتفعيلها في السوق، ارتفعت عدد الجلسات التي تم عقدها في السوق عام 2010 حيث بلغت (237) جلسة تداول بمعدل خمس جلسات أسبو عيا وبنسبة 55.92\% وفقا لانطلاق استثمار ات جديدة في السوق و إقرار القوانين من أجل بيئة استثمارية سليمة، انخفضت عدد الجلسات التي تم عقدها في السوق عام 2011 إلى (232) جلسة نداول أي بنسبة 2.1\%- وبمعدل خمس جلسات أسبو عيا على الرغم من التقدم التقني والإداري في السوق، وتذبذبت عدد الجلسات ما بين الارتفاع و الانخفاض في السوق وفقا لعوامل يتعرض لها السوق وبالتالي يؤدي إلى تأثر مؤشرات التداول حتى عام 2015 بلغت عدد الجلسات التي تم عقدها (233) جلسة تداول أب بنسبة 2.6\% على الرغم من الآزمة الاقتصادية التي تعرض لها العراق نتيجة خفض أسعار النفط إلا أنه لم يكن له تأثير كبير على الجلسات التي عقدت في السوق، وارتفعت عدد الجلسات عام 2016 حيث بلغت (234) جلسة تداول أي بنسبة 0.4\% ، وبلغت عام 2017 (239) جلسة نداول أي بنسبة 2.1\% نتيجة الوعي الاستثماري لاى المساهمين و عمليات الإفصاح و الثفافية التي يقوم بها السوق و إقبال مستثمرين أجانب للاستثمار في شتى قطاعات الاستثمار، وفي عام 2018 انخفضت عدد الجلسات التي عقدت في سوق العراق للأوراق المالية نتيجة حدوث خلل في عمليات التداول بالنسبة لعدد من الثركات حيث بلغت (238) جلسة تداول أب بنسبة 0.4\%- وبمعدل خمس جلسات أسبو عيا .

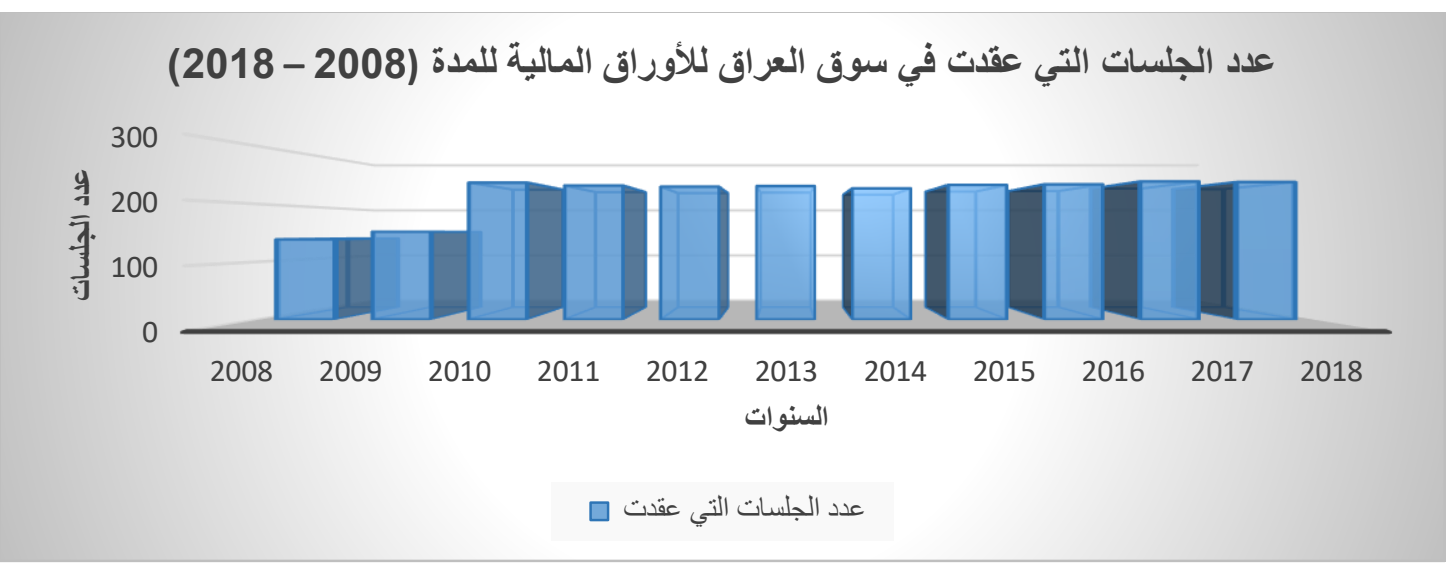

شكل(7) :عدد الجلسات التي عقدت في سوق العراق للأوراق المالية للمدة (2008 - 2018) 
المصدر : من إعداد الباحثة بالاعتماد على بيانات جدول رقم (6) ، والموضح فيه عدد الجلسات التي عقدت في سوق العراق للأور اق المالية .

يبين شكل رقم (7) إن عدد الجلسات في سوق العر اق للأوراق المالية متز ايدة من سنة لأخرى خلال سنو ات الدر اسة مما يعني أن هذا مؤشر لكفاءة وفعالية السوق و أنشطته المتكافئة التي تولد تزايد مستمر على مدى السنوات. (ISX) (Iraq Stock Exchange Index) سابعا - مؤشر الأسعار يستخدم سوق العراق للأوراق المالية مؤشر قياسي مئوي يعتمد على قياس حركة التغير في أسعار أسهم عينة من الثركات المساهمة التي نقوم بتداول اسهمها بانتظام و عددها (37) شركة تمثل قطاعات السوق، إذ يتم تثبيت أوزان جلسة الأساس وقياسها على أنها 100\% يجري بعدها قياس المؤشر في كل جلسة وفقا إلى مقارنة قيمته بتلك القيمة، وبعدها مقارنة قيمته في جلسة اليوم بقيمته في الجلسة التي سبقتها لتعيين عدد نقاط الارتفاع أو الانخفاض في قيمة المؤشر بالنقاط. . جدول(7): مؤشر الأسعار (ISX) في سوق العراق للأوراق المالية للمدة (2008 - 2018)

\begin{tabular}{|r|r|r|}
\hline (ISX) مؤشر الأسعار & (IS) & 2008 \\
\hline- & 58.36 & 2009 \\
\hline $72.8 \%$ & 100.86 & 2010 \\
\hline $0.12 \%$ & 100.98 & 2011 \\
\hline $34.71 \%$ & 136.03 & 2012 \\
\hline$-8 \%$ & 125.02 & 2013 \\
\hline$-9.49 \%$ & 113.15 & 2014 \\
\hline$-18.6 \%$ & 92 & 2015 \\
\hline$-26 \%$ & 773.56 & 2016 \\
\hline$-11 \%$ & 64.48 & 2017 \\
\hline$-10 \%$ & 58.54 & 2018 \\
\hline$-12.1 \%$ & 51.12 & \\
\hline
\end{tabular}

المصدر : من إعداد الباحثة بالاعتماد على بيانات التقارير السنوية لسوق العراق للأوراق المالية للمدة (2008 - 2018) . من خلال الجدول أعلاه نلاحظ أن مؤشر الأسعار (ISX) في سوق العراق للأوراق المالية حيث شهد العديد من التذبذبات وفقا للأوضاع التي تحيط بالسوق، ففي عام 2008 شهد المؤشر ارتفاعا المالية العالمية في ذلك العام، وفي عام 2009 أغلق المؤشر لأسعار الأسهم المتداولة في السوق عند (100.86) نقطة وبنسبة تغير 72.8\% وفقا للتقنية التكنولوجية الحديثة المستخدمة في ألية التداول في السوق، وأغلق المؤشر عام 2010 عند (100.98) نقطة وبنسبة ارتفاع 0.12\% حيث أخذ المؤشر عام 2010 
لقياس حركة التغير في أسعار أسهم (40) شركة مساهمة في السوق، وارتفع مؤشر الأسعار في سوق العراق للأوراق المالية عام 2011 حيث أغلق عند (34.71\% 34.03 وأيضا احتسب على أساس (40) شركة مساهمة في السوق، حيث كان هذا الارتفاع نتيجة التطور التقني والوظيفي في السوق، وانخفض مؤشر الأسعار عام 2012 ليخلق عن (125.02) نقطة وبنسبة نغير 8\%- ، استمر بالانخفاض حتى عام 2013 على الرغم من استحداث أنظمة التداول في السوق و إدار الك المستثرين بالاستثمار ومدى أهميته حيث أغلق عند (113.15) نقطة وبنسبة انخفاض 9.49\%- واعتمد في قياس حركة التغير في أسعار اسهم (37) شركة مساهمة في السوق، وفي عام 2013 انخفض المؤشر على الرغم من اطلاق مؤشر ISX30 الذي يعتمد على (37) شركة جيدة من حيث المساهمة وتم شطب الشركات الضعيفة من حيث التداول، و أيضا تم خلال هذا العام إدر اج شركة اتصال جديدة و هي شركة أسياسيل حيث بلغ المؤشر (113.15) وبنسبة 9.49\%- و استمر بالانخفاض حتى عام 2015 إذ أصبح إلى (73.56) نقطة وبنسبة 26\%- حيث تم احتساب المؤشر اعنبار ا من 9/2/2015 حيث أطلق عليه مؤشر (ISX 37) و إلى باقي السنوات بالتغير في أسعار أسهم (37) شركة مساهمة في السوق مما يسبب فارق كبير مقارنة بالسنوات السابقة، وسجل المؤشر عام 2016 (64.48) نقطة وبنسبة 11\%- مقارنة بعام 2015 ، وفي عام 2017 أغلق عند (58.54) نقطة وبنسبة 10\%- وأغلق مؤشر الأسعار في سوق العراق للأوراق المالية عام 2018 عند (51.12) نقطة وبنسبة 12.1\%- ، حيث يعود هذا الانخفاض لعو امل اقتصادية تحيط بالسوق ووفقا للازمة السياسية التي يعاصر ها البلد .

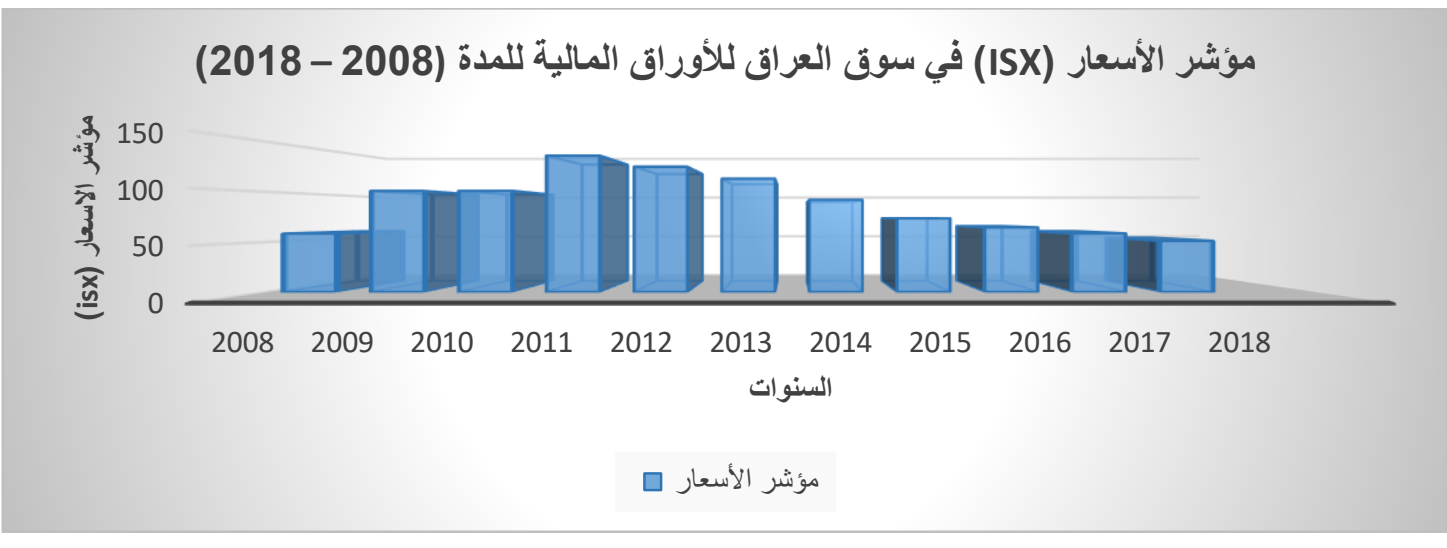

$$
\text { شكل(8): مؤشر الأسعار (ISX) في سوق العراق للأوراق المالية للمدة (2008 - 2018) }
$$

المصدر : من إعداد الباحثة بالاعتماد على بيانات جدول رقم (7) والموضح فيه مؤشر الأسعار في سوق العراق للأوراق المالية. يبين شكل رقم (8) إن مؤشر الأسعار في السوق انخفض بشكل ملحوظ ابتداء من عام 2015 حيث نم اتخاذ نظام جديد يعتمد على عدد من الثركات وتبلغ (37) شركة ، ونتيجة عدم استقرار الأوضاع المحيطة بالبلد مما يؤثر على مؤشر السوق بشكل 


$$
\text { ثنامنا - معدل دوران الأسهم }
$$

ويعد معدل دوران الأسهر من المؤشرات المهمة التي يأخذها المستثر بعين الاعتبار قبل اتخاذ قرار الاستثمار بالأوراق المالية ، كما أنه يعتبر أحد مؤشرات المفاضلة لبس فقط فيما بين الأسهم المدرجة في سوق ما بل تتعدى ذلك ليشمل المفاضلة فيما بين الأسواق المالية المختلفة بالنسبة للمستثرين الأجانب، ويرتبط معدل دوران الأسهم بشكل مباشر بعدد أيام التداول وبالتالي تتأثر يتأثر هذا المعدل بإجاز ات الأعياد التي تتخلل أثنهر التداول مع الأخذ في الاعتبار أن ارتفاع هذا المعدل قد يرتبط بارتفاع و انخفاض مؤشرات السوق وليس في اتجاه واحد. ويتم احتسابه بقسمة عدد الأسهم المتداولة على عدد الأسهم المدرجة (رؤوس

$$
\text { معدل دوران الأسهم = عدد الأسهم المتداولة - عدد الأسهم المدرجة (رؤوس الأموال) }
$$

\begin{tabular}{|c|c|c|}
\hline نسبة التغير \% & معدل دوران الأسـه (مرة) & السنة \\
\hline- & 13.11 & 2008 \\
\hline $6.7 \%$ & 14 & 2009 \\
\hline$-1.5 \%$ & 13.79 & 2010 \\
\hline $45.03 \%$ & 20 & 2011 \\
\hline$-11.9 \%$ & 17.62 & 2012 \\
\hline $7.32 \%$ & 18.91 & 2013 \\
\hline$-30.5 \%$ & 13.14 & 2014 \\
\hline$-45.9 \%$ & 7.1 & 2015 \\
\hline $56.3 \%$ & 11.1 & 2016 \\
\hline$-4.5 \%$ & 10.6 & 2017 \\
\hline$-34.9 \%$ & 6.9 & 2018 \\
\hline
\end{tabular}

جدول(8): معدل دور ان الأسهم في سوق العراق للأوراق المالية للمدة (2008 - 2018)

المصدر : من إعداد الباحثة بالاعتماد على بيانات التقارير السنوية لسوق العراق للأوراق المالية للمدة (2008 - 2018) . نلاحظ من خلال بيانات جدول رقم (8) معدل دوران الأوراق المالية في سوق العراق للأوراق المالية خلال سنوات الدراسة، حيث نلاحظ تذبذب معدل دوران الأسهر خلال السنوات وذلك حسب معدلات الشركات المدرجة في السوق من حيث مدى قوة عملياتها في السوق، فقي عام 2008 بلغ معدل دوران الأسهم (13.11) مرة وفي عام 2009 بلغ معدل دوران الأسهر (14) مرة وبنسبة زيادة مقدارها 6.7\% وذللك لكثرة عمليات التداول بالأسهم في السوق نتيجة إدخال نظام التداول الإكتروني في السوق مما ساعد على زيادة العمليات وبالتالي تحقيق دور ان أعلى للأسهم، في عام 2010 انخفض معدل دور ان الأسهم بنسبة ـ 1.5\% حيث بلغ (13.79) مرة وذللك نتيجة وجود عدد من الظروف الاقتصادية والسياسية التي تحيط بالسوق، شهد عام 2012 ارتفاع ملحوظ جدا على مدى سنوات الدراسة حيث بلغ (20) مرة وبنسبة ارتفاع بلغت 45.03\% حيث زادت حركة تداو لات 
الأسهم بصورة جيدة مما أدى إلى ارتفاع معدل دوران السوق، وتذبذب معدل دوران الأسهم للسنوات اللاحقة بين الهبوط و الارتفاع تبعا لظروف سياسية واقتصادية تؤثر على نشاط السوق بصورة عامة حيث انخفض معدل دوران الأسهم عام 2012 بنسبة 11.9- ، وارتفع عام 2013 بنسبة 7.32\% نتيجة دخول قطاع جديد إلى السوق مما زاد من حركة الأسهم في السوق وارتفاع معدلات تداولها ، وفي عام 2014 انخفض بنسبة 30.5\%- ، وفي عام 2015 بنسبة 45.9\%-، وشهد عام 2016 ارتفاع معدل دوران الأسهم حيث بلغ (11.1) مرة وبنسبة ارتفاع 56.3\% ، وبلغ معدل دوران الأسهم عام 2018 (6.9) مرة

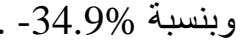

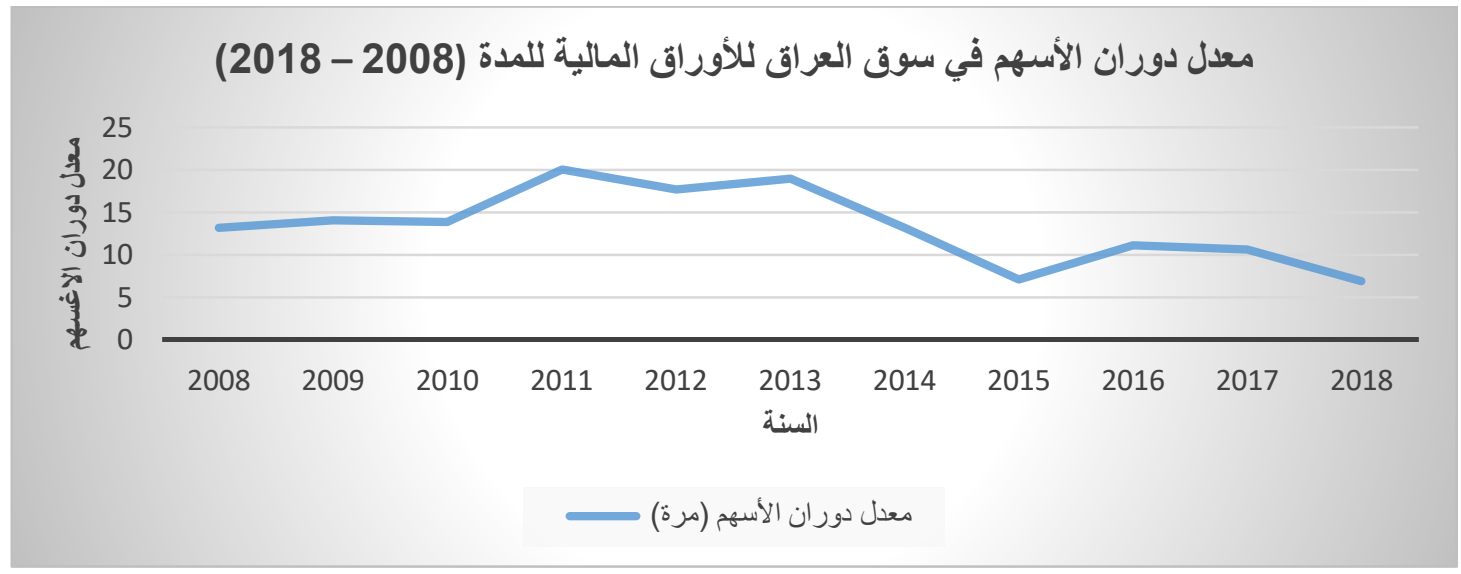

شكل(9): معدل دوران الأسهم في سوق العر اق للأور اق المالية للمدة (2008 - 2018) المصدر : من إعداد الباحثة بالاعتماد على بيانات جدول رقم (8) الموضح فيه معدل دوران الأسهم في السوق . يوضح شكل (9) أن معدل دوران الأسهم في سوق العراق للأوراق المالية منذبذب إلى حد كبير نتيجة الأوضاع الاقتصادية التي تؤثر على السوق، وكان المعدل في أعلى مستوياته عند عام 2013 و عام 2011 . 


\section{المبحث الثالث}

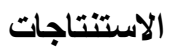

توصلت الدراسة لعدد من الاستتناجات ومن أبرز ها :

1) إن استخدام نظـام التداول الإلكتروني كبديل لنظـام التداول اليدوي والإيداع أعطى مرونـة كبيرة ومعلومـات مختلفة للوسطاء سهلت عليهح معرفة العمليات المنفذة وغير المنفذة وإجر اء تحليل لأوضاع الثركات المتداولة أسههها بشكل أسرع وتحقيق شفافية و أمسان للمتعاملين و المستثمرين في السوق قد أسـهم في رفع كفاءة وسر عة التعامل بـالأوراق المالية، إذ بلغت عدد الأسهم المتداولة في سوق العراق للأوراق المالية عام 2018 (832) مليار سهم، الأمر الذي يحقق المزيد من العدالة والسرعة و السهولة في تنفيذ الأو امر. 2) إن مؤشرات التداول في سوق العراق للأوراق المالية ارتفعت بنسبة كبيرة بعد استحداث نظام التداول في السوق، على الرغم من بعض الانخفاضات بسبب عو امل أثرت فيها مما ساهم برفع أداء سوق العراق للأوراق المالية وزيادة

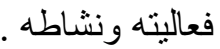

3) أدى التداول الإلكتروني إلى فرصة الحصول على زيادة عمليات التداول في السوق وتسهيل تتفيذ الصفقات والعقود الكبيرة اذ بلغت عدد العقود المنفذة عام 2018 (91,067) عقد . إن الأدوات الاستثمارية المتعامل بها في سـوق العراق للأوراق المالية محدودة جدا وتقتصر عمليات التداول على أسهم الشركات المتداولة فقط، يعود ذلك كون السوق لم يتعامل بالأوراق المالية الأخرى (السندات، شهادات الإيداع المصرفية، الخ) و اقتصاره على الأسهم فقط. 5) قوة البنية التحتية لسوق العراق للأور اق المالية من حيث مكاتب الاستعلام وشركات الوساطة والوسطاء الإلكترونيين في السوق، والتي تؤدي دوراً كبيرًا في تسهيل وصول الخدمات الاستثمارية لنرائح المستثرين واستخدمها بشكل

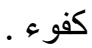

6) هنالك استجابة سريعة لاستخدام نظام التداول الإكتروني إذ بلغ معدل الجلسة الواحدة للتداول عام 2017 (5.08) ل ل الجلسة مما يجعل للتذاول:

الإلكتروني دوراً مهماً في تعزيز عمليات التداول في سوق العراق للأوراق المالية .

8) تنامي مؤشر القيمة السوقية لسوق العر اق للأوراق المالية بعد تطبيق نظام التداول الإلكتروني وذلك من خلال زيادة حركة تداول أسهمه وارتفاع قيمته السوقية، حيث بلغ عام 2018 (11350) مليار دينار عراقي . 
إن مؤشر الأسعار في سوق العراق للأوراق المالية والذي يستخدم في تقييم الآداء الكلي للسوق، ويستخدم كذلك

كمقياس للحركـة العامـة لسوق الأوراق المالية، تراوح بين الارتفاع والانخفاض، إذ بلغ عام 2011 (136.03) نقطة عندما كان يقيس المؤشر 100 شركة، وفي عام 2015 بلغ (73.56) نقطة بمقياس 37 شركة .

\section{التوصيات}

في ضوء الاستنتاجات سابقة الذكر في المبحث الأول من هذا الفصل فان الدر اسة الحالية توصي بما يأتي : 1) توفير أنظمة أمن وحماية متظورة لحماية ومر اقبة أنظمة التداول الإلكترونية وشبكات الاتصال بالإضافة لتشغيل منظومة متكاملة لأحدث أنظمة النسخ الاحتياطي وحفظ البيانات بحيث يضمن أمن وسرية المعلومات واستمرارية أعمال وخدمات السوق والمركز في كافة الظروف، من أجل المحافظة على عمليات التداول الإكتروني من الاختر اق و التناعب والاحتبال التي قد تحدث بسبب اختراق شبكات الإنترنت الخاصة بسوق العراق للأوراق المالية ومركز الإيداع العر اقي .

2) تعزيز أفضـل الممارسـات وتشجيع التحسينات في عمليـات الإفصــاح عـن المعلومـات مـن قبـل الـشركات المدرجــة.

3) تحفيز المناخ الاستثماري في سوق العراق للأوراق المالية، ليتم استقطاب العديد من الثركات الأجنبية للاستثمار وذللك عن طريق توفير بيئة آمنة تتسم بالاستقرار الاقتصادي والأمني، فضلا عن منح الضمانات المناسبة للمستثرين الأجانب وتخفيض الرسوم الجمركية لجذب المزيد من الاستثمارات . 4) تقوية وتمتين استخدام وسائل تكنولوجيا البيانات و المعلومات في سوق العر اق للأوراق المالية مما يساعد على زيادة وتعظيم عمليات التداول في السوق . 5) تنويع الأدوات المالية الحديثة من أجل أن يتم التعامل بها في سوق العراق للأوراق المالية من السندات وشهادات الإيداع، من أجل توسع نطاق الاستثمار ات لكافة الثركات و القطاعات . 6) إن الإجراء الثاسع والسديد لألية التداول الإلكتروني يمكن أن يكون مستمر ا خلال فترة زمنية مقبلة، إذ يكون لله الأثر الو اضح بتجنب الأخطاء البشرية ومنح التقة ونشر الثقافة للمستثرين، وفتح ميادين استثمارية جديدة، وينجم عن هذا النشاط المنز ايد تحسين متز ايد للسيولة وارتفاع تدريجي في كفاءة المعلومات . الحرص المستمر على تحديث الأنظمة الخاصة بتقنية السوق بهدف تقديم خدمات ذات كفاءة عالية في تنفيذ عمليات التداول، و إجراء عمليات التسجيل والإيداع و المر اقبة وأنظمة نوزيع بيانات ومعلومات السوق . 
ARID International Journal of Social Sciences and Humanities (AIJSSH) VOL.2, Special Issue (1), August 2020

8) دعوة الثركات الخاصة غير المدرجة في سوق العر اق للأور اق المالية لأقبالها للمشاركة في السوق باعتبار ها شركات مساهمة ومدرجة في سوق العراق المالية، إذ نوفر هذه المساهمة إمكانية كبيرة لها من أجل توفير الأموال اللازمة و السيولة كونه يساهم في النمو المستقبلي لهذه الثركات وفي الوقت نفسه يزيد من فعالية وأنشطة سوق العراق للأور اق المالية .

9) البحـث عـن طرق بديلة للتـداول في سوق العراق للأوراق المالية في حسال حـدوث مخـاطر للتـداول الإلكتروني و التي تتمثل في التوقـات المفاجئـة والعطلات التي يتعـرض لهـا النظـام خـلال العـل اليومي للسوق وضمان استمرار عمل السوق بشكل طبيعي. 


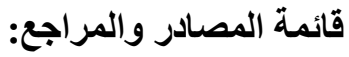

$$
\begin{aligned}
& \text { [1] التقرير السنوي لسوق العراق للأوراق المالية ، سوق العراق للأوراق المالية ، } 2014 \text { ـ } \\
& \text { [2] التقرير السنوي لسوق العراق للأوراق المالية ، سوق العراق للأوراق المالية ، } 2015 \text { ـ } \\
& \text { [3] التقرير السنوي لسوق العراق للأوراق المالية ، سوق العراق للأوراق المالية ، } 2016 \text { ـ } \\
& \text { [4] التقرير السنوي لسوق العراق للأوراق المالية ، سوق العراق للأوراق المالية ، } 2019 \text { ـ }
\end{aligned}
$$

[5] A . Hirt , Geoffery , "Investment Management" , Mcgraw - Hill, Abusiness Unit Of The Mcgraw - Hill Companies , Inc. Of The Amoricas , New York, America , 2012.

[6] Backet, Michael \& Essen, Yvette , "How The Stock Markets Works" , Third Edition, Koga Page, London \& Philadelphia , 2010 .

[7] Gopal, Crama , "Manaegment Of Finncial Services" , House Pvt Ltd, India , 2014 .

[8] Gorham, Michael \& Singh, Nidhi, (Electronic Exchange The Global Transformation Form Pits To Bits), Elsevier Inc., America, 2009.

[9] Hammer , Stephanie, "Architects Of Electronic Trading Technology Leaders Who Are Shoping Today's Financial Markets", John Willey \& Sons , Canada , 2013.

[10] Harris , L. , "Liquidity, trading rules, and electronic trading systems" , New York University Salomon Center, Leonard N. Stern School of Business , New York , 1990.

[11] J.Grimm , Danid, "A Process Of Natural Correction : Arbitrage And The Regulation Of Exchange - Traded Funds Under The Investment Coompany, Act , 2000 .

[12] J.J. Welfens , Paul, "Internet Comomics . Net Macroeconomics , Deregulation And Innovation", Springer . Verlag, Bretin, 2002 .

[13] Janssen , Marijn \& J.Scholl, Hans \& A.Wimmor, Maria \& Tan , Yao-Hua , "Electronic Government", Springer Heidelberg, London , 2011.

[14] Jong , Frank De \& Rindi , Barbara , "The Microstructure Of Financial Markets" , First Published In Print Format, Published In The United State By Cambridge University Press New York, America , 2009.

[15] Liebenberg, Lauren, "The Electronic Financial Of Markets Of The Future" , Palgrave Macmillan, 2002 .

[16] M , Blennerhassett \& R.G ,Bowman, "A Change In Market Microstructure : The Switch To Electronic Screen Trading On The Newzlannd Stock Exchange" , Journal Inter National Financial Markets , 1998 .

[17] Machiraju , H.R , "International Financial Markets And India", Second Edition, New Age International Ltd Publishers , 2002 . 
[18] N. Gregoriou , Greg , "The Handbook Of Trading" , The Mcgraw-Hill Companies , USE , 2010 .

[19] R.Bell , Adrian , Brooks , Charis \& Prokopczuk , Marcel, "Handbook Of Research Methods And Application In Empirical Finance" , Edward Elgar Cheltenham , USA, 2013.

[20] Rossignoli , Cecilia \& Ricciardi , Francesca, "Inter - Organizational Relationships Towards A Dynamic Model For Understanding Business Network Performan" , Springer International , 2015 .

[21] S . Mishkin , Fredcric \& G . Eakins, Stanley, "Financial Markets And Institutions", This Print Edition Is Published By Arrangement With Pearson Education, Inc And Dorling Kindersley 2018 .

[22] Yamaguch , Yutaka , "The Lmplications Of Electronic Trading In Financial System" , 2001 , (3) .

[23] حمدون ، ريان هاشم ، "التنظيم القانوني للتداول الإلكتروني للأوراق المالية" ، الطبعة الأولى ، دار الجامعة الجديدة ، الإسكندرية ، مصر ، 2013.

[24] السحيباني ، محمد ، بن إبراهيم ، " نظام التداول الإلكتروني في سوق طوكيو المالية والسوق المالية السعودية : دراسة مقارنة" ، كلية الاقتصاد و العلوم الإدارية - جامعة الإمام محمد بن سعود الإسلامية ، السعودية ، 2007 . [25] سعيد ، غفر ان حاتم ، مسلم ، حمدية شاكر ، سعيد ، عفر اء هادي ، "أثر الازمة المالية العالمية على كفاءة نشاط سوق العر اق للأور اق المالية در اسة قياسية للمدة (2006 - 2008)" ، مجلة العلوم الاقتصادية والإدارية ، المجلد 19 ، العدد 71 ، العر اق ، 1013 [26] الضبع ، اشرف ، "تسوية عمليات البورصة" ، دار النهضة العربية ، القاهرة ، مصر ، 2007 . 